\title{
Imagem e espaço em pinturas de vaso e escultura arquitetônica: sobre a (ir)relevância do suporte
}

\author{
Nikolaus Dietrich ${ }^{[1]}$
}

\begin{abstract}
Resumo
Este artigo explora a relevância do suporte no estudo da arte da Grécia Antiga, através de uma análise paralela da relação entre imagem e espaço na pintura de vasos áticos e escultura arquitetônica. Enquanto produções acadêmicas recentes e inovadoras sobre arte grega tentam focar na incomensurabilidade de diferentes suportes da representação pictórica, este artigo mostra analogias essenciais. As imagens encontradas em ambos os meios pictóricos provam abranger uma definição mais ampla que a de corpo físico. Em vez disso, nenhum limite claro pode ser definido entre o corpo físico e suas "extensões" - armadura, vestimenta, características, em alguns casos até elementos do contexto espacial da imagem como, por exemplo, "paisagem". Enquanto esse espaço (presumido) que a cerca pode ser parte intrínseca da imagem, a ideia do espaço pictórico dissociado da estrutura material está ausente, tanto na pintura do vaso quanto na escultura arquitetônica. Em vez disso, o espaço das figuras é idêntico à sua estrutura material, seja na área de pintura do vaso ou no frontispício de um templo. Palavras-chave: pinturas de vasos; escultura arquitetônica; representação do espaço.
\end{abstract}

\section{Figura y espacio en la pintura de Járron y en la escultura Arquitetónica: en la (ir-) relevancia del medium}

\section{Resumen}

A través de una análisis paralelamente de la relación entre la figura y el espacio en la pintura sobre los jarrones áticos y la escultura arquitetónica, este artículo explora la importancia del medium en el estudio del arte griega. Mientras que la pesquisa recente destaca la incomensurabilidad de diferentes médiuns de la representación de la imagen, ese artículo plantea la analogia. En esos dos médiuns de la imagen, la figura tiene la intención de comprender más do que solamente el cuerpo físico. Ninguna frontera clara se puede ser trazada entre eso y sus « extensiones » - armas, ropas, atributos, o mismo elementos del contexto espacial de la figura, su « paisaje ». Mientras que ese (supuesto) espacio circundante puede ser una parte intrínseca de la figura, la ideia de un espacio pictório disociado del escenário material de la imagen no es ni en la pintura sobre jarrones, ni siquiera en la escultura arquitetónica. Por el contrário, el espacio de las figuras muestra ser idéntico al escenário material de la imagen, que este sea el campo de la imagen sobre un jarrón, o un frontón de un templo.

Palabras-clave: pintura sobre jarrones; escultura arquitetónica; representación del espacio.

\section{Figure and space in vase painting and in architectural sculpture: on the (ir-)relevance of the medium}

\section{Abstract}

The present article explores the relevance of medium in the study of Ancient Greek art by a parallel analysis of the relationship of figure and space in Attic vase painting and architectural sculpture. While innovative recent scholarship on Greek art tends to emphasize the incommensurability of different media of pictorial representation, this article shows essential analogies. The figures found in both pictorial media prove to comprise more than the physical body definition. Instead, no clear border can be drawn between the physical body and its "extensions"-armor, clothing, attributes, in some cases even elements of the figure's spatial context as e.g., "landscape." While such (presumed) surrounding space can be an intrinsic part of the figure, the idea of a pictorial space dissociated from the material frame is absent from both vase painting and architectural sculpture. Instead, the figures' space is identical with their material frame, be it the picture field on a vase, or the pediment of a temple. Keywords: vase painting; architectural sculpture; depiction of space.

\section{Figure et espace dans les peintures de vase et sculpture architecturale: sur le (ir-) relevance du médium}

\section{Résumé}

Par une analyse parallèle de la relation entre la figure et l'espace dans la peinture sur vases attiques et la sculpture architecturale, cet article explore la relevance du médium dans l'étude de l'art grec. Alors que la recherche récente avait tendance à souligner l'incommensurabilité de différents médiums de représentation picturale, cet article met en avant l’analogie. Dans ces deux médiums de l’image, la figure s'avère comprendre plus que le seul corps physique. Aucune frontière nette ne peut être tracée entre celui-ci et ses « extensions » armes, vêtements, attributs, ou même des éléments du contexte spatial de la figure, son "paysage ». Alors que ce (soi-disant) espace environnant peut être une partie intrinsèque de la figure, l'idée d'un espace pictural dissocié du cadre matériel de l'image ne se retrouve ni dans la peinture sur vases, ni dans la sculpture architecturale. Tout au contraire, l'espace des figures s'avère identique au cadre matériel de l'image, que ce soit le champ d'image sur un vase, ou le fronton d'un temple.

Mots-Clés: peinture sur vases; sculpture architecturale; représentation de l'espace.

Artigo recebido em 29 de abril de 2015 e aprovado para publicação em 8 de setembro de 2015

[1]Professor de Arqueologia Clássica do Institut für Klassische Archäologie da Universidade de Heidelberg - Heidelberg - Alemanha. E-mail: nikolaus.dietrich@zaw.uni-heidelberg.de 

duais não simplesmente como uma manifestação universal da arte de um certo período, mas para estarmos atentos às diferenças de tamanho, material, técnica, função, contexto espacial, contexto de exibição, público-alvo etc., ou, resumindo: para diferenças no suporte. ${ }^{2}$ Essa conscientização pelas diferenças no suporte pictórico levou a uma prática muito comum no estudo da problemática da arte Grega: tirar conclusões dessas categorias de pinturas bem representadas e incluí-las nessas categorias de pinturas menos (ou nem um pouco) representadas em nossa cultura material. Isso diz respeito, especialmente, aos esforços de conhecer a história da pintura parietal grega através da análise das pinturas em vasos, ${ }^{3}$ e sobre a história das esculturas eretas gregas, através da análise da escultura arquitetônica ou pela observação das cópias romanas de mármore das estátuas gregas de bronze. ${ }^{4}$ Dessas três analogias feitas entre diferentes meios de representação pictórica, aquela entre cópias

2Obviamente, não é possível fundamentar isso por nenhuma bibliografia completa. Alguns exemplos interessantes e particulamente expressivos devem ser suficientes. Além disso, deve-se enfatizar aqui que, embora haja um interesse comum nos aspectos particulares da imagética antiga nos estudos sobre a Antiguidade, o termo “medium”, é principalmente usado por pesquisadores alemães. Sobre o potencial geral de uma perspectiva em torno dos suportes na imagética Antiga, ver Muth; Petrovic (2012, p. 281-318). Bons exemplos de ênfase sobre a especificidade do suporte pictórico na pesquisa acadêmica são os importante e inovadores trabalhos de Robin Osborne sobre escultura arquitetônica do fim dos anos 1980 até hoje. Ver Osborne (1987; 1994; 2000; 2009). Osborne explora, em especial, as implicações que o contexto visual das imagens dispostas em construções (especialmente templos) têm sobre sua interpretação. Um bom exemplo que aborda o crescente interesse sobre questões de material e técnica usadas nas esculturas gregas e como elas podem ser um fator determinante na forma final das imagens está na obra de Luca Giuliani (2005), sobre as primeiras esculturas arcaicas de mármore. Nesse contexto observe ainda, por exemplo, o trabalho desenvolvido nas duas últimas décadas sobre os detalhes da estatuária em bronze, em oposição à escultura em mármore. Ver, por exemplo, Mattusch (1988; 1996; 2014). No campo da pintura de vasos, outro suporte pictórico abordado neste artigo, muitos trabalhos pioneiros de Lissarrague tentam mostrar a relevância do suporte pictórico específico do "vaso" pintado em vários aspectos: os contextos da utilização, o manuseio dos vasos, a circularidade do objeto pintado, sua bilateralidade, as várias formas dos campos de pintura e como tudo isso afeta a visualização das pinturas (ver especialmente a obra de François Lissarrague [1987]). Dos muitos artigos ver, por exemplo, os mais recentes de Lissarrague (2009a ; 2009b). Uma abordagem mais geral do suporte pictórico, em oposição ao texto, também se tornou um campo de pesquisa na arqueologia clássica, onde o suporte provou ser uma forte linha de pensamento. Para a pintura de vasos, essa perspectiva produziu os resultados mais interessantes na obra de Giuliani (2003) sobre a formação e o desenvolvimento da iconografia narrativa na arte grega clássica e arcaica, especialmente, mas não somente, na pintura de vasos, ou em Muth (2008), sobre violência na pintura de vasos áticos, defendendo uma perspectiva do suporte, em vez de uma interpretação historicista do desenvolvimento entre o início do século VI e o fim do século $\vee$ a.C.

${ }^{3}$ Embora a pintura de vasos áticos já tenha recebido atenção considerável a partir do trabalho pioneiro de J. Beazley em meados do século XX, o principal objetivo continuou sendo estudar a história do estilo grego em geral e, consequentemente, destacar as pinturas dos vasos (suporte). Provavelmente, o verdadeiro marco no interesse acadêmico pela pintura de vasos aconteceu com Claude Bérard (1984), quando o estudo de potes e recipientes pintados finalmente se emancipou das pesquisas mais amplas da história da arte, abrindo caminho para pelos menos duas novas perspectivas, uma mais iconográfica e semiótica (Bérard) e outra mais interessada na antropologia da imagem (Lissarrague).

${ }^{4}$ São dignas de nota as tentativas, desde os anos 1970, de conhecer a história da arte/escultura gregas através de originais, na medida do possível, e manter as cópias romanas fora de escopo ou, pelo menos, fazer uma clara distinção entre os originais e as cópias. Ver, por exemplo, Ridgway (1970; 1981) e Boardman (1985; 1995), com mais confiança nas cópias romanas, mas ainda fazendo uma clara distinção entre originais e cópias. Robin Osborne é consistente em evitar basear sua abordagem nas cópias romanas em Osborne (1998). Curiosamente, em estudos mais tradicionais da academia alemã sobre escultura, essa tendência é bem menos predominante (ver, por exemplo, o recente manual sobre escultura grega de Bol (2002-2010). Ver ainda uma interessante tentativa de basear um discurso somente em pinturas, para as quais dispomos de informação contextual no (curtíssimo) ensaio sobre arte grega de Hölscher (2007). 
romanas e originais gregas provavelmente foi a que causou maior impacto na formação da "arte grega", tanto dentro como além do meio acadêmico.

Neste artigo, abordarei unicamente em vasos e escultura arquitetônica e, mais especificamente, o conceito de espaço e "paisagem" nessas duas categorias de imagens, finalmente levantando a questão sobre se o suporte é ou não um fator decisivo na espacialidade da representação pictórica. Assim, devo abordar uma grande questão metodológica através de um estudo de caso bem definido. As conclusões resultantes desse exemplo certamente não resolverão totalmente o assunto em questão - mas elas podem nos ajudar a questionar crenças estabelecidas na suposta totalidade - incluindo a relevância do suporte. Para evitar um mal entendido, gostaria de enfatizar imediatamente que meu objetivo não é argumentar contra a conscientização do suporte no estudo da imagética na Grécia Antiga, mas motivar pesquisadores a buscar não somente diferenças nos suportes, mas também analogias entre - que com frequência são bem diferentes - os suportes para representação pictórica.

\section{O que é uma figura?}

Uma das características gerais da arte grega, com a qual pode-se facilmente concordar, é o lugar central dedicado à imagem humana. Inversamente, "natureza" e "paisagem", como conhecemos da pintura pós-Renascentista europeia, estão surpreendentemente ausentes na maioria das pinturas gregas, especialmente em obras dos períodos Arcaico e Clássico. ${ }^{5}$ Dois vasos áticos muito diferentes - uma ânfora produzida por volta de 540 a.C. (fig. 1) ${ }^{6}$ e um lekythos, provavelmente de 440 a.C. (fig. 2) ${ }^{7}$ - oferecem uma observação interessante sobre essas duas hipóteses relativas à arte grega, confirmando-as e, ao mesmo tempo, levantando questões críticas. A ânfora em Boston, pintada em estilo semelhante ao de Exéquias, mostra o deus Dionysos sentado em meio a uma grande videira. Doze sátiros, desenhados em escala menor, sobem na videira, ocupados com a colheita, como as grandes cestas no chão fazem o espectador compreender. Ao olhar para a pintura, repleta com a vegetação, pode parecer difícil sustentar a hipótese de que a natureza não tinha lugar na arte grega. Ao contrário, a pintura no lekythos do Pintor de Aquiles em Munique mostra duas

\footnotetext{
5Essa é uma visão da história da arte antiga há tempos estabelecida e já observada na opbra de Löwy (1900). O mesmo argumento também é visto em literatura mais recente. Ver, por exemplo, Hölscher (2003, p. 165). Como consequência, não há muitos estudos sobre paisagem ou elementos de paisagem na arte grega. Ver, por exemplo, Woermann (1876), Heinemann (1910), Pfuhl (1923, § 327), Bernert; Lorenz (1933), Elliger (1975, p. 3-8), Pfitzner (1937), Nelson (1976), Carroll-Spillecke (1985), Hurwit (1991), Chazalon (1995), Siebert (1996), Zanoni (1998), Hedreen (2001), Himmelmann (2005), LaRocca (2008), Dietrich (2010, p. 11-18). ${ }^{6}$ Boston, Museum of Fine Arts 63.952; Para 62, 317: perto de Exéquias; CVA Boston I, pl. 12.1-3; BA 350462. Nessa ânfora, como tipicamente em representações da natureza na arte grega (pré-Helenística): Hurwit (1991, p. 32). A discussão a seguir sobre essa pintura se baseia em minha análise de Dionysos e videiras em: Dietrich (2010, p. 71-79).

${ }^{7}$ Munique, Antikensammlung S 80; ARV 997.155, 1568, Para 438: Pintor de Aquiles; CVA Munique XV, pl. 33.1-3, 34.1-4 e 35.2; BA 213977. A discussão a seguir repetirá parciamente Dietrich (2010, p. 300-302). Ver também a obra recente de Kunze-Götte (2009, p. 55-57).
} 
figuras femininas quase que exclusivamente. Uma aparece de pé na base da área da pintura; a outra está sentada sobre um fino traço de relevo. Esse traço obviamente expressa algum tipo de elevação do terreno. Pode-se imaginar que ele seja rochoso - mas talvez não haja necessidade de especificar mais essa indicação tão mínima de "paisagem." Claramente a pintura não convida o espectador a explorar a natureza exata daquela elevação: em contraste com as videiras da ânfora em Boston, esse elemento da paisagem fica completamente atrás da figura. Significativamente, a linha de relevo se estende somente a alguns centímetros além da figura sentada e, então, desaparece no fundo branco do vaso, deixando todas as perguntas que um espectador poderia eventualmente fazer sobre a natureza exata daquela "paisagem" sem resposta: como podemos entender o trecho do terreno irregular, onde a figura da direita está sentada, até a base, sobre a qual está a figura da esquerda de pé? Como podemos considerar o limite no canto direito da pintura, onde o terreno rochoso minimamente indicado "se transforma" no fundo branco neutro do vaso? A pintura não responde a essas perguntas. A conclusão mais óbvia a que podemos chegar aqui é que o espectador não deve imaginar que pode fazer essas perguntas.

\section{Uma das características gerais da arte grega, com a qual pode-se facilmente concordar, é o lugar central dedicado à imagem humana}

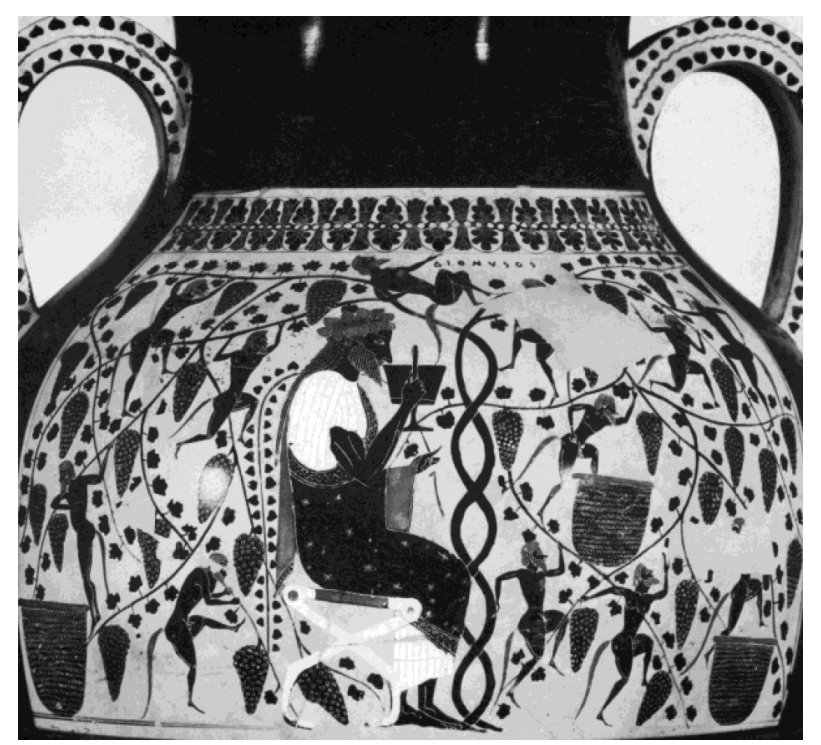

Figura 1: Ânfora ática de figuras negras, ca. 540 a.C. (Boston, Museum of Fine Arts 63.952), com Dionysos entre videiras. 


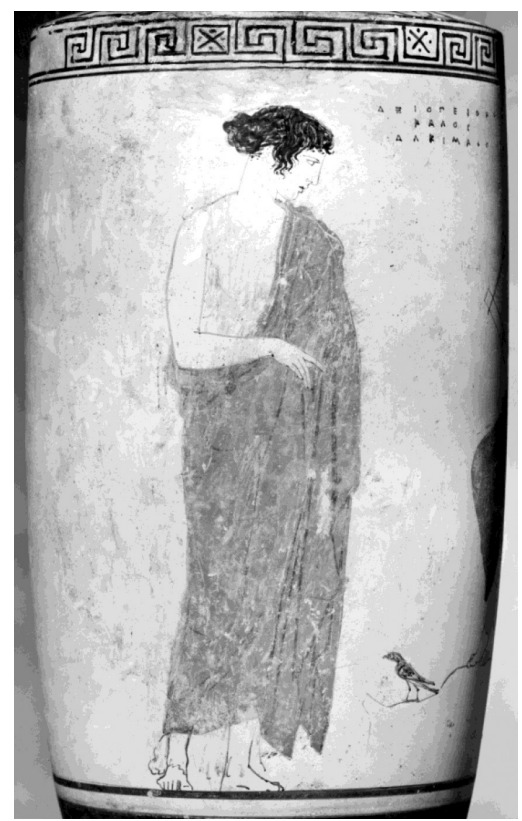

Figura 2A: Lekythos ático de fundo branco, ca. 440 a.C. (Munique, Antikensammlung S 80), com mulher to-

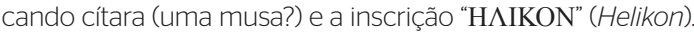

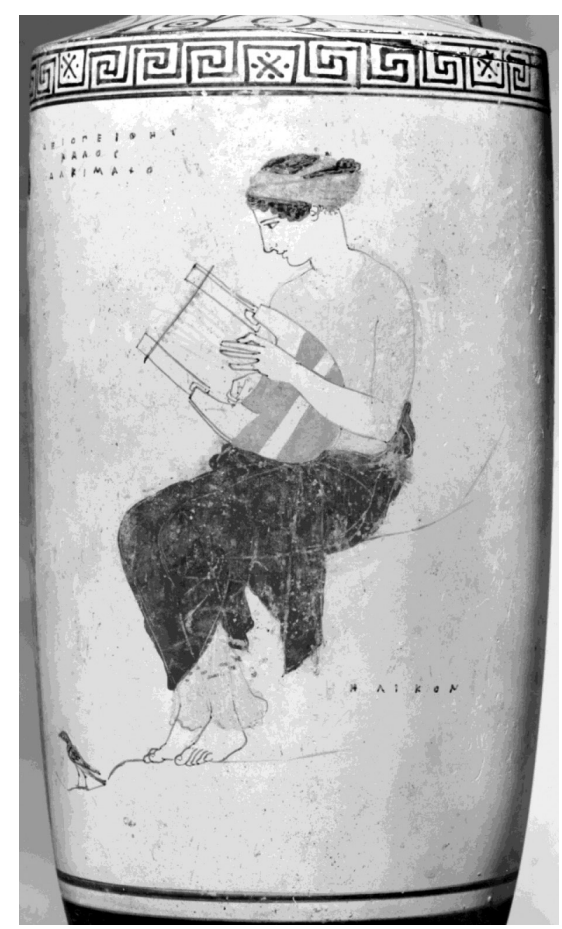

Figura 2B

Assim, em uma pintura, o ambiente natural das figuras recebe atenção especial e em outra, um século mais recente, aquele ambiente natural - embora indicado por um fino traço de relevo - parece bastante irrelevante. Como podemos explicar essa diferença? Pela diferença no contexto - o symposion para a 
ânfora e o contexto fúnebre para o lekythos? Pela diferença de data - o arcaico posterior e o alto classicismo? Essas duas explicações podem ser facilmente descartadas: Nos vasos de symposion, traços de relevo não são de forma alguma mais explícitos sobre a paisagem que eles retratam que aqueles presentes no lekythos de Munique. ${ }^{8}$ Da mesma forma, o fenômeno das folhagens cobrindo toda superfície disponível na área da pintura pode ser encontrado em todos os tipos de vasos áticos de figuras negras do período Arcaico Tardio, incluíndo vasos não relacionados à esfera do symposion. ${ }^{9}$ Quanto à possível explicação cronológica, existe a ideia tradicional encontrada na literatura mais antiga, sobre a existência de uma maior afinidade com a paisagem no período da arte Arcaica Tardia sob a influência jônica, contrastando com o foco mais exclusivo na figura humana encontrado na arte do período Clássico, que teria se distanciado da influência oriental e se tornado mais verdadeiramente "grega." Claramente, essa ideia é mera ilusão. Fora o argumento ético claramente desatualizado nela intrínseco, essa teoria se baseia em poucas evidências, consistindo essencialmente em um pequeno número de pinturas muito analisadas e superestimadas como, por exemplo, a famosa Taça Milesiana do Louvre, conhecida como "coupe à l'oiseleur." ${ }^{10}$ Dessa forma, contexto e cronologia as duas formas padrão para explicar diferenças na Arqueologia Clássica - não nos ajudarão aqui. Vamos voltar, então, aos nossos dois vasos e, mais especificamente, a duas inscrições neles encontradas, que nos ajudarão a formular a pergunta de forma ainda mais clara. Sob a figura sentada no lekythos de Munique, lemos uma inscrição "HᄉIKON" [helicon], denominando não uma pessoa como era comum, mas um lugar/paisagem, a famosa montanha das musas, o Monte Hélicon. ${ }^{11}$ Por que encontramos essa inusitada ocorrência, de um toponimo em uma imagem em vaso ático, numa pintura cujo o único elemento de paisagem consiste nos rudimentos de uma linha de relevo? Na ânfora de Boston, achamos a inscrição menos impactante " $\triangle \mathrm{IONY} \Sigma \mathrm{O} \Sigma$ " (dionysos) (Dietrich 2010, p. 75-76). Denominar uma figura por uma descrição já perfeitamente reconhecível através da iconografia é mais usual em pinturas em vasos

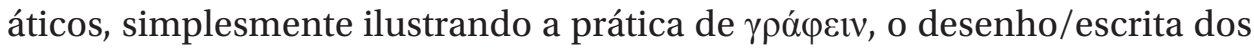
pintores/oleiros atenienses. A posição da inscrição na área da pintura, e não o que nela está escrito, pede uma investigação mais profunda. De fato, em vez de ser colocada próxima à figura de Dionysos, como sempre, a inscrição está

\footnotetext{
¿Sobre a falta geral de um significado iconográfico próprio das linhas de relevo, ver Dietrich (2010, p. 245-253). ${ }^{9}$ Sobre videira e hera cobrindo a área da pintura em imagens de vasos áticos de figuras negras mais tardios, ver Dietrich (2010, p. 177-230). Para o contexto presente, ver particularmente Dietrich (2010, p. 198-199).

10Louvre F 68; CVA Louvre VIII, III He, pl. 78.3, 5 e 8; ca. 550 a.C. Ver, por exemplo, os comentários sobre a Taça Milesiana na obra de Heinemann (1910, p. 68-70, fig. 10). Essa ideia é encontrada em obras tão antigas quanto as de Schefold (1967, p. 39-41). Para uma resposta sobre a presumida origem jônica da representação da paisagem, ver Nelson (1976, p. 23, nota 31), com mais literatura.

${ }^{1} \mathrm{G}$. Hedreen usa essa inscrição como evidência para sua interpretação geral dos elementos da paisagem como representações de localidades específicas. Ver Hedreen (2001, p. 183). Como mostrarei aqui, isso passa ao largo da questão. Para uma breve visão geral sobre o uso de inscrições em vasos, ver Osborne; Pappas (2007). Para uma pesquisa mais abrangente, ver Immerwahr (1990). As contribuições mais significativas ao estudo de inscrições em vasos gregos podem ser encontradas nas inúmeras publicações de Lissarrague sobre esse assunto. Ver, por exemplo, Lissarrague (1985; 1987, p. 119-133; 1992; 1995; 1999a; 2013). Ver também a obra de Steiner (2007, p. 74-93), e Georg Gerleigner (futura).
} 
grafada sob a faixa de moldura ornamental e bem acima dos troncos entrelaçados da videira, perto de um sátiro que sobe (embora o nome não se refira a ele). A razão prática desse posicionamento incomum da inscrição do nome provavelmente é a falta de espaço. Se a inscrição tivesse sido incluída quando a pintura das figuras estivesse terminada, não haveria mais nenhum canto livre na área da pintura, bastante preenchida por videiras e sátiros. Por que, então, o pintor simplesmente não abdica da inscrição do nome redundante? $\mathrm{O}$ fato de a inscrição estar mais perto do sátiro que de Dionysos, aparentemente não preocupou o pintor. Mas talvez seja até possível encontrar uma razão positiva para esse posicionamento.

Numa ânfora da mesma época cujo estilo é semelhante ao do Pintor de Princeton, também vemos Dionysos sentado e cercado de videiras, com sátiros em escala menor subindo pelos galhos, embora aqui as videiras não cresçam da terra. Dionysos as segura em suas mãos (Dietrich, 2010, p. 77, fig. 56). ${ }^{12}$ A videira aqui é compreendida como uma particularidade do deus, o que inclui os sátiros em escala menor. Em outra ânfora do Pintor de Príamo com uma pintura muito semelhante àquela ânfora de Boston; as videiras com sátiros subindo crescem tanto da terra quanto se originam da mão de Dionysos (fig. 3) (Dietrich 2010, p. 70-73). ${ }^{13}$ Se as videiras crescem da terra sobre a qual Dionysos está sentado, ou se elas crescem diretamente de sua mão, a pintura captura a mesma ideia básica: elas mostram Dionysos como aquele que oferece o vinho, fazendo as videiras e as uvas crescerem. Se essa ideia é transmitida por ele transformar a videira num atributo que ele segura nas mãos ou não, a videira é parte intrínseca da visualização de Dionysos como o deus do vinho. A conclusão a que chegamos a partir daí, com relação à ânfora de Boston é clara: a inscrição " $\triangle \mathrm{IONY} \Sigma \mathrm{O} \Sigma$ " se refere não somente à figura de Dionysos, mas ao deus $e$ seu dom. A figura de Dionysos e as videiras crescendo a seus pés constituem uma unidade inseparável, o que significa que a inscrição do nome, colocada em cima dos troncos entrelaçados, é muito bem posicionada.

Assim, a rica representação das videiras na ânfora de Boston, que parecia contradizer a centralidade da figura humana na arte grega, ao mostrar a atenção especial do pintor ao ambiente natural prova ser outra confirmação dessa ideia: o suposto ambiente natural transformou-se numa extensão da figura principal, intrinsecamente ligada a ela. O crescimento da vinhas por toda pintura manifesta a presença invasiva de Dionysos no vaso.

Contudo, ao confirmar a centralidade da figura humana (ou, nesse caso, divina), essa imagem nos força a repensar o conceito de uma figura e perguntar se é possível distinguir completamente a figura de seu ambiente. Essa pergunta está intrinsecamente ligada à questão da paisagem na imagética, como pode ser observado na história da pintura de paisagens na Europa. De fato, a pintura de paisagem inicialmente se desenvolveu dos segundos planos das pinturas de temas Bíblicos ou mitológicos, ganhando independência ao longo

12Londres, Market (Sotheby 's 8-9.12.1986); ca. 540-530 a.C. BA 16657.

${ }^{13}$ Roma, Villa Giulia 2609 (106463); Para 146.8ter; ca. 520 a.C.; BA 351080. 
do tempo em relação ao conteúdo narrativo, até a paisagem finalmente se tornar o tema principal em si mesma. ${ }^{14} \mathrm{Na}$ pintura de paisagem europeia, a diferença essencial entre espaço ao redor como entidade independente, por um lado, e as figuras representadas nesse espaço, por outro, é uma condição sine qua non. Em nossa ânfora de Boston, entretanto, se a figura de Dionysos não tivesse sido incluída na pintura, as videiras perderiam sua razão de ser e também desapareceriam!

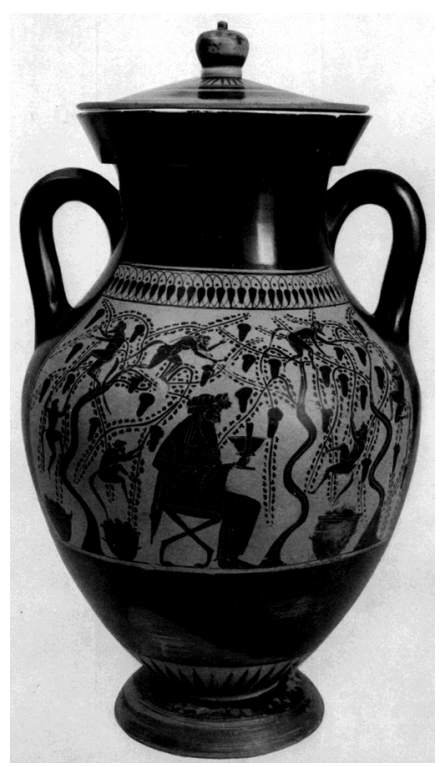

Figura 3: Ânfora ática de figuras negras, ca. 520 a.C. (Roma, Villa Giulia 2609 (106463), com Dionysos entre videiras crescendo tanto da terra quanto de sua mão.

O que queremos dizer com "figura," então, e onde deveríamos estabelecer seus limites? O corpo humano é uma entidade bem definida, como se pode imaginar: um torso, uma cabeça, duas pernas e dois braços - e inúmeras imagens gregas fizeram dessa entidade seu principal tema, ou até mesmo exclusivo como, por exemplo, os kouroi arcaicos. Ainda assim, este corpo humano pode ter "extensões." Comparando um torso de Samos arcaico em mármore, em Berlin, vestindo uma couraça (fig. 4) (15 $^{15}$ um dos raros exemplos de estatuária masculina arcaica não-nua - com outra, kouroi nus, parece que o adorno da couraça destaca precisamente aquelas características anatômicas que recebem atenção especial em representações nuas de torsos masculinos: o peito saliente, o arco

\footnotetext{
${ }^{14}$ Essa explicação basilar sobre o desenvolvimento da pintura de paisagens independentes de seus primórdios até os séculos XVI XVII pode ser encontrada em qualquer manual sobre pinturas de paisagens europeias. Ver por exemplo Büttner (2006) para considerações muito mais ricas e complexas.

${ }^{15}$ Berlin, Antikensammlung 1752 (outros fragmentos ainda em Samos, depósito II do Heráion S 23. I 210); ca. 520-510 a.C. Ver também Maderna-Lauter (2002, p. 265, fig. 351a-d), Blümel (1963, p. 45-46, fig. 112-115), FreyerSchauenburg (1974, p. 158-162), Martini (1990, p. 61-63, fig. 18).
} 
costal, a linha alba e o umbigo. ${ }^{16}$ Em vez de cobrir o torso, a couraça o reproduz através da ornamentação, adaptando-se ao corpo. Certamente, a couraça não se funde completamente ao corpo - não há perigo real de confundí-lo com um peito nu. Por outro lado, uma má interpretação pode facilmente acontecer, como no caso do torso do arqueiro de mármore de aproximadamente 470 a.C. descoberto na Acrópolis de Atenas (fig. 5) (Schrader, 1939). ${ }^{17}$ Ainda sobre o mármore: somente a parte inferior da couraça é retratada plasticamente. No restante, a couraça se adapta estritamente ao corpo nu.

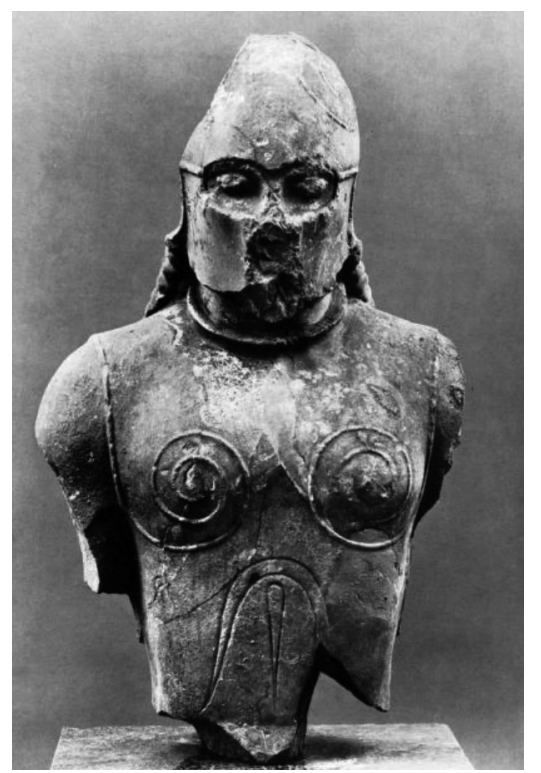

Figura 4: Torso arcaico de um guerreiro com couraça, de Samos, ca. 520-510 a.C. (Berlin, Antikensammlung 1752)

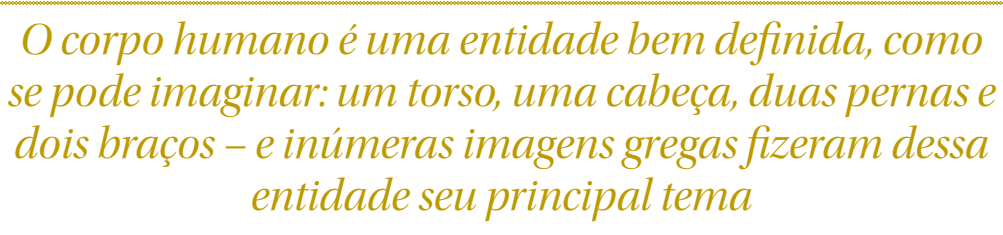

A pintura produziu coisas inequívocas, como mostra a reconstrução da cor de Brinkmann. Ainda assim, a representação do corpo masculino armado destaca a completa aderência da armadura ao corpo, mas certamente não o dualismo entre o próprio corpo da figura e algum equipamento externo. A aderência da couraça ao corpo é especialmente bem ilustrada em alguns vasos

\footnotetext{
${ }^{16}$ Quase todas as estátuas de kouros nus poderiam servir de exemplo aqui, como revela a obra de Richter (1970). Reconhecidamente, a similaridade estrutural de como a anatomia é representada é menos óbvia no modelo mais plástico do corpo dos kouroi contemporâneos que nas representações mais lineares de kouroi mais antigos, em meados do século VI a.C. (ver, por exemplo, o kouros de Ptoion no museu de Tebas, inv. 3, e Karanastassis (2002, p. fig. 254).

${ }^{17}$ Atenas, Museu da Acrópolis 599. Sobre a policromia da estátua e a reconstrução de sua cor, ver Brinkmann (2003) e Brinkmann; Scholl (2010, p. 149-153).
} 
áticos do estilo Arcaico Tardio, numa época em que os pintores começaram a demonstrar interesse em detalhar a rotação do abdômen, numa transição das pernas em perfil com o peito frontal. Mais surpreendentemente, essa rotação é representada com frequência até quando a figura é de um hóplita armado usando uma couraça. Este é o caso, por exemplo, de uma ânfora com de figuras negras em Rhodes, que retrata Héracles lutando com as Amazonas (fig. 6). ${ }^{18}$ A parte inferior da couraça da Amazona é mostrada de perfil e a parte superior de frente, como se sua armadura fosse elástica e colada ao corpo. Aqui, a ideia de corpo e armadura como unidade inseparável foi aparentemente "mais forte" que a impossibilidade prática de uma couraça dura se adaptando ao movimento do corpo. Se a nudez é uma roupa, então a armadura é "uma nudez" (Bonfante, 1989)...

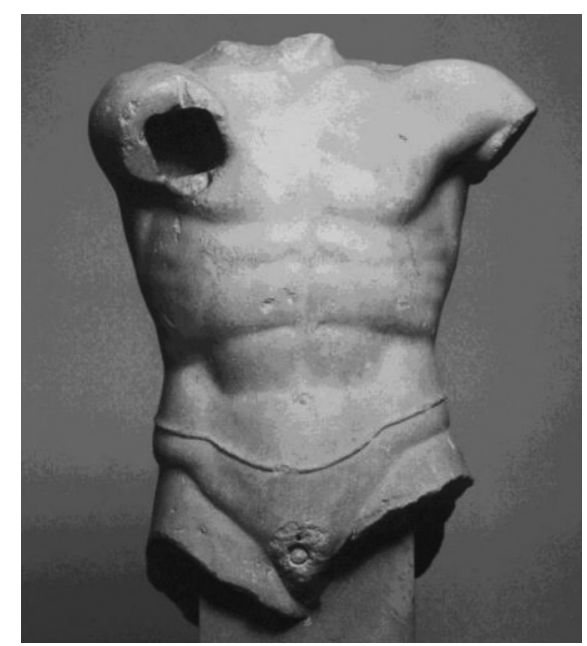

Figura 5: Torso de um arqueiro, com couraça totalmente 'fundida' ao corpo, da Acrópolis atenense (Atenas, Museu da Acrópolis 599), ca. 470 a.C.

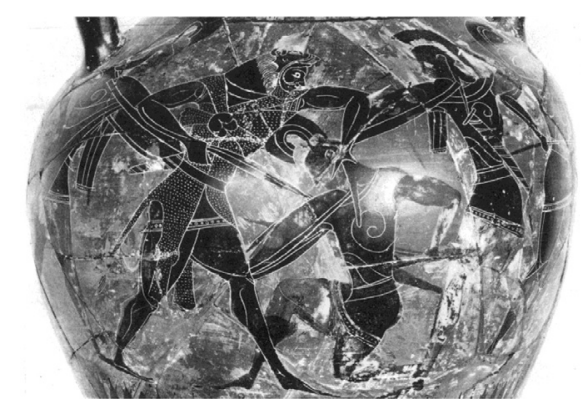

Figura 6: Ânfora ática de figuras negras, ca. 520-500 a.C. (Rhodes, Museu Arqueológico 301637), com Héracles lutando com as Amazonas. A couraça da Amazona de joelhos é mostrada de perfil em sua parte inferior e sua parte superior, de frente, como se ela fosse um adorno elástico, colado a seu corpo.

\footnotetext{
${ }^{18}$ Rhodes, Museu Arqueológico 301637; ABV 315.5: Pintor de Bucci; CVA Rhodes I, III.H.e.3, III.H.e.4, pl. 4.1, 3; BA 301637. Em vasos de figuras vermelhas mais antigos são encontradas soluções até mais complicadas para a representação da rotação da couraça. Ver, por exemplo, a couraça de Menelau na taça de Douris, ca. 480 a.C. em Paris (Louvre G 115; ARV 434.74, 1583, 1653, Para 375: Douris; ver Buitron-Oliver (1995), pl. 71, nr. 119; BA 205119).
} 
Esses exemplos demonstram que não se pode definir um limite claro entre o corpo de uma figura e sua armadura. ${ }^{19} \mathrm{~A}$ icônica pele do leão de Héracles nos dá outro exemplo de extensão de corpo que representa uma perfeita simbiose. Na figura de Héracles na taça de Eufronios, em Munique (fig. 7), ${ }^{20}$ a pele de leão está perfeitamente sobreposta no corpo, resultando numa duplicidade entre a cabeça do herói e a do leão. A unidade do corpo e sua "segunda pele" evidentemente contém simultaneamente uma dimensão ética: a ferocidade, a força e a coragem do leão complementam o corpo do herói em perfeita correspondência. ${ }^{21}$

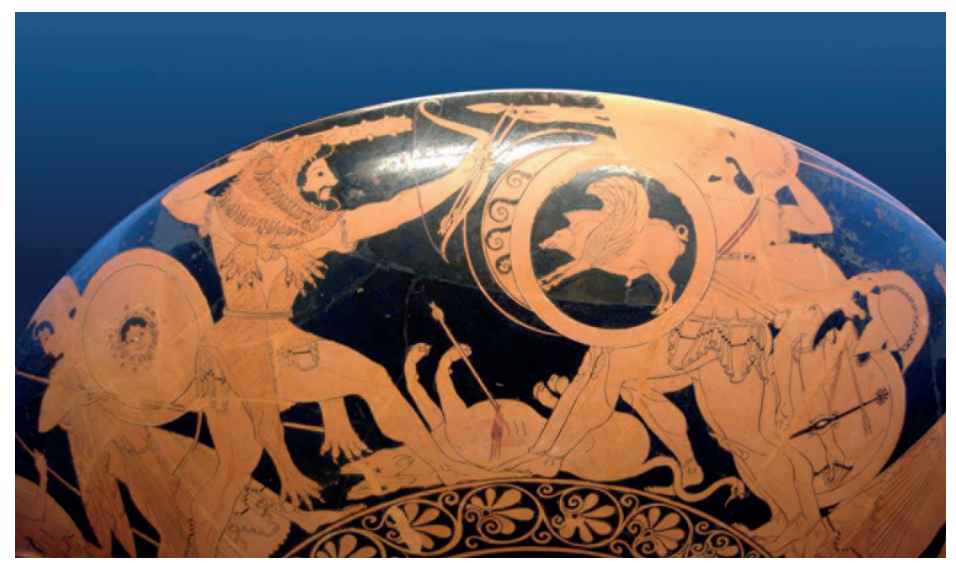

Figura 7: Taça ática de figuras vermelhas do pintor Eufronios, ca. 510-500 a.C. (Munique, Antikensammlung 2620), Héracles lutando contra Gerião com a pele de leão duplicando sua cabeça.

Em função da aderência e da simbiose do corpo com relação às suas extensões nas figuras do hóplita ou de Héracles serem tão completas, a dissociação dos dois é importante o suficiente para ser representada. Isso pode explicar porque a cena do hóplita colocando sua armadura, vista aqui em uma ânfora do Pintor de Amasis, em Boston, mostrando o paradigma mítico dessa cena genérica: Aquiles recebendo suas armas de Tétis. (fig. 8), ${ }^{22}$ adquiriu enorme popularidade nas pinturas em vasos áticos. ${ }^{23}$ De modo semelhante, o grande significado atribuído à pele do leão e as armas pendurados na representação de Héracles nu, em luta agonística, como na cratera de Eufronios no Louvre ${ }^{24}$ ou na ânfora em Munique (fig. 9) ${ }^{25}$ surge da estreita coesão do corpo do herói e sua "segunda pele": é a coesão do corpo e do equipamento que faz sua separação

\footnotetext{
${ }^{19}$ Coisas semelhantes poderiam ser ditas sobre o corpo e a idumentária femininos. Sobre isso, ver Dietrich (no prelo).

20Munique, Antikensammlung 2620; ARV 16.17, 1619, Para 322, 379: Eufronios; ca. 510-500 a.C.; BA 200080 ${ }^{21}$ Sobre a sobreposição completa da pele de leão em Héracles, ver Lissarrague (1999b, p. 161-162).

22Boston, Museum of Fine Arts 01.8027; ARV 152.27, 687, Para 63: Pintor de Amasis; CVA Boston I, pl. 27.1-2, 28.3; BA 310454.

${ }^{23} \mathrm{Há}$ ampla literatura sobre cenas nas quais guerreiros recebem armas e partem para a guerra. Ver Lissarrague (1984; 1990, p. 35-69), e Spieß (1992)

${ }^{24}$ Paris, Louvre G 103; ARV 14.2, 1584, 1619, Para 322: Eufronios; CVA Louvre I, III.Ic.4, pl. 4.1-4, 5.1-3; ca. 510 a.C.; BA 200064.

${ }^{25}$ Munique, Antikensammlung 1557; ABV 290.3: Pintor de Bolonha 441; CVA Munique VIII, pl. 392.3, 395.1-2, 397.3; ca. 520-500 a.C.; BA 320344.
} 
ser merecedora de uma encenação tão impactante. No caso da luta, Héracles nu, a separação de seus atributos enfatiza sua nudez agonística, como já argumentei em outra ocasião (Dietrich, 2010, p. 327-334). ${ }^{26}$

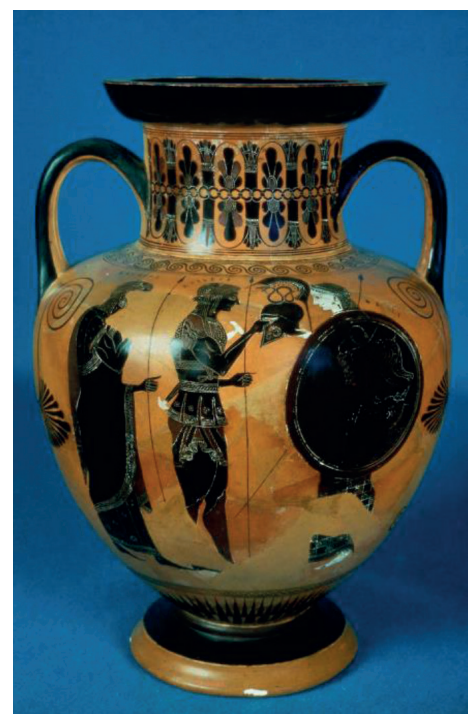

Figura 8: Ânfora ática de figuras negras, ca. 530-520 a.C. (Boston, Museum of Fine Arts 01.8027), a armadura de Aquiles.

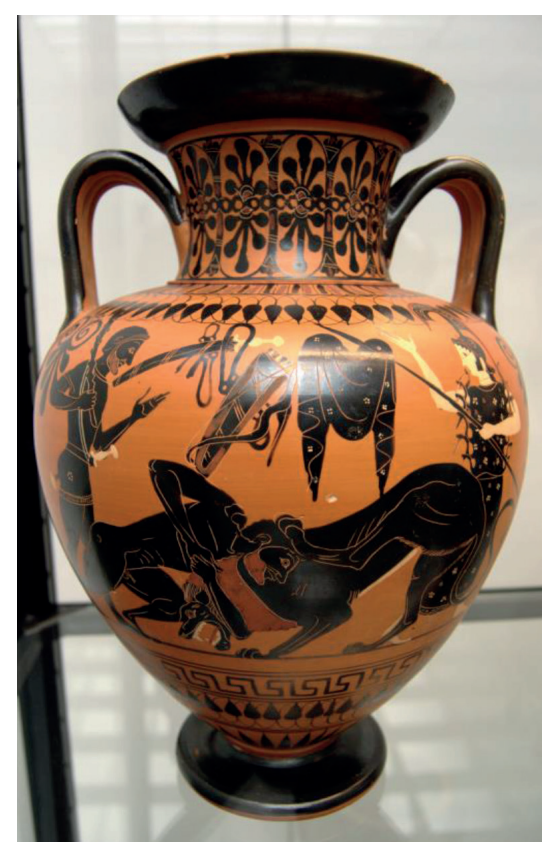

Figura 9: Ânfora ática de figuras negras, ca. 520-500 a.C. (Munique, Antikensammlung 1557), Héracles e o leão, os atributos do herói estão espalhados por toda área da pintura.

${ }^{26}$ Outro exemplo de separação impactante e significativa do corpo do herói de seus atributos/armadura é a famosa ânfora de Exéquias na Bolonha, que mostra Ajax se preparando para cometer suicídio (Bolonha, Musée Communal 558; ABV 145.18, Para 60: Exéquias; ca. 530 a.C.; BA 310400). 
Ao enfatizar a separação do corpo de seu equipamento, a razão de as armas e a armadura terem sido deixados de lado, da mesma forma, tem o efeito de aumentar a figura ao preencher a área mais completamente com o herói. Expandir a figura além de seus limites corporais é precisamente o efeito produzido pelas videiras da ânfora de Boston - um preenchimento não no sentido tradicional horror vacui (horror ao vácuo), mas como forma de aumentar e intensificar a presença de Dionysos no vaso. Muitas figuras dionisíacas - o próprio Dionysos, sátiros, mênades - se prolongam semelhantemente através de galhos, que literalmente emanam de seus corpos e se espalham pela área da pintura. A taça com olho pintado (fig. 10) ${ }^{27}$ e a ânfora (fig. 11) ${ }^{28}$ mostram dois exemplos desse fenômeno muito comum nas pinturas de vasos de figuras negras do período Arcaico Tardio. Como já demonstrei em outro estudo, esses galhos devem ser entendidos como plantas trepadeiras, que cobrem a suferfície do vaso em incansável crescimento e indicam a presença, a vida e o movimento reais das figuras (Dietrich, 2010, p. 216-224). A partir do fim do século VI a.C. em diante, esse método de fazer os corpos "irradiarem" além de seus limites físicos se generalizou para qualquer figura. Isso pode ser visto numa taça exposta no Cabinet des Médailles de Paris, que retrata Aquiles perseguindo o cavaleiro Troilo, com galhos indicando essa ação através da direção de seu crescimento (fig. 12) $\cdot{ }^{29}$ Embora isso possa forçar a credulidade de alguns leitores para designar os atributos de Héracles como extensões de seu corpo, como fiz acima, essa formulação se aplica muito diretamente às videiras se espalhando pela área da pintura: elas evidenciam o alcance dos corpos pintados, seu "raio de ação" na superfície do vaso.

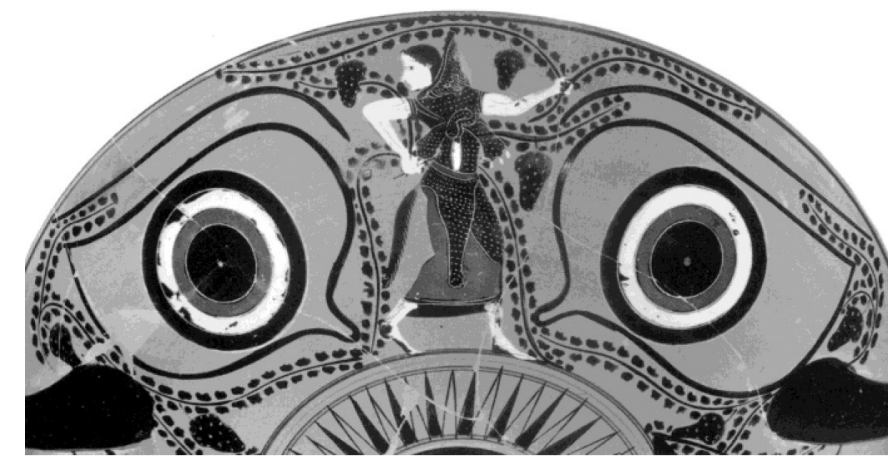

Figura 10: Taça ática de figuras negras com olho pintado, ca. 530-520 a.C. (Munique, Antikensammlung 2052), com mênade dançando e segurando vinhas.

\footnotetext{
${ }^{27}$ Munique, Antikensammlung 2052; ABV 206.7, Para 95, 97: Group of Walters 48.42; CVA Munique XIII, pl. 24.1 8; ca. 530-520 a.C.; BA 302640.

${ }^{28}$ Madri, Museo Arqueologico Nacional 11008; ABV 253.1, 294.24, ARV 7.2, 1618, Para 128, 321: Psiax; CVA Madrid I, III He 8-9, pl. 23.1a-b, 24.1-2, 25.1-2, 26.1; ca. 520-510 a.C.; BA 200022.

${ }^{29}$ Paris, Cabinet des Médailles 330; CVA Paris, Bibliothèque Nationale de France II, pl. 54.3-7; ca. 500-490 a.C.; BA 11356. Ver sobre essa taça Dietrich (2010, p. 196-198). Como um método de representação geral, que não se restringe mais ao domínio dionisíaco, esses galhos posteriores com frequência carecem de qualquer especificação botânica.
} 


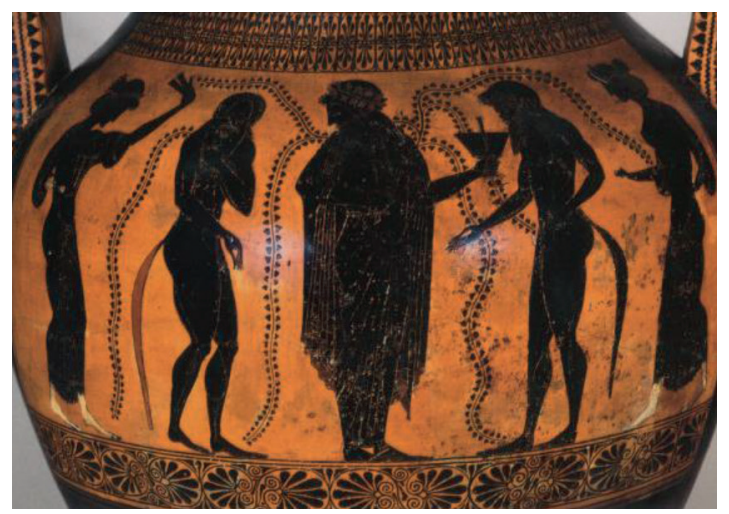

Figura 11: Ânfora ática de figuras negras, ca. 520-510 a.C. de Psiax (Madri, Museo Arqueologico Nacional 11008), Dionysos com sátiros, mênades e ramos de hera saindo da figura central do deus, se espalhando por toda área da pintura.

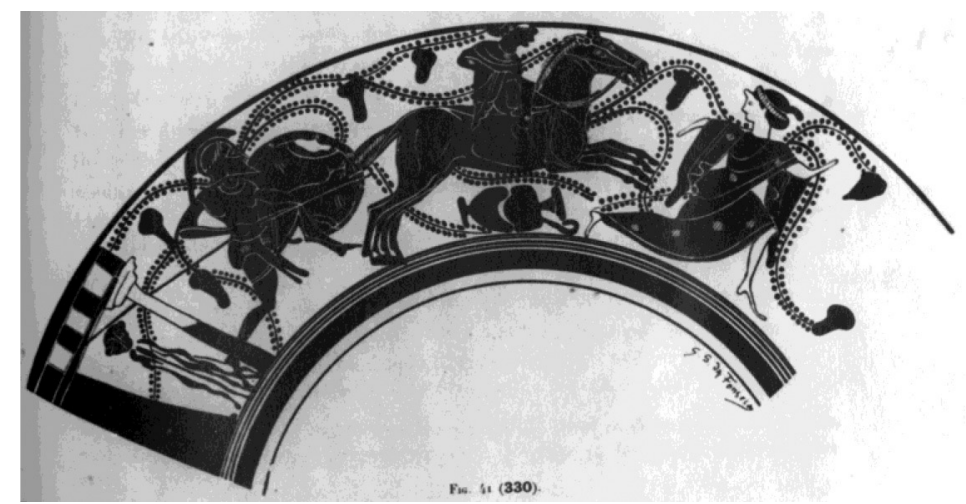

Figura 12: Taça de figuras negras, ca. 500-490 a.C. (Paris, Cabinet des Médailles 330), Aquiles perseguindo Troilo. Galhos reforçam o movimento e a ação pela direção de seu crescimento.

Onde devemos, então, traçar os limites do corpo? O corpo físico formado por um torso, uma cabeça, dois braços e duas pernas é, obviamente, uma entidade bem definida - pelo menos na perpectiva contemporânea. ${ }^{30}$ Mas será que não perderíamos a essência do herói ao reduzirmos sua figura ao corpo físico? Sua velocidade de movimento, o alcance de sua força, o objetivo de suas ações - não seriam esses, igualmente, elementos essenciais do corpo pintado de Aquiles, isto é, de sua figura? A "permeabilidade" do corpo, sua suscetibilidade de assumir (o que chamamos de) atributos que realçam seu poder foi destacada por Jean-Pierre Vernant, sem se referir especificamente a imagens (Vernant, 1986; Hölscher, 2003, p. 167). Poderíamos dizer que os atributos de Héracles na figura 9 não se limitam a um meio de identificação, mas também constituem uma parte essencial da figuração do herói como ele é. Eles evidenciam

\footnotetext{
${ }^{30}$ Devemos nos lembrar aqui que na linguagem do início da Antiguidade grega, o corpo físico não é uma entidade e uma unidade claramente definida. De fato, a palavra $\sigma \tilde{\omega} \mu \alpha$ (soma), abrangendo o corpo físico como um todo, é usada somente por Homero para designar o corpo morto (ver LSJ), enquanto o corpo vivo é tipicamente referido por sua parte mais característica e não como uma unidade orgânica única. Sobre esse conceito homérico de corpo, ver Snell (1975, p. 13-29), especialmente p. 16. Sobre como isso pode fazer diferença na interpretação das origens da imagética grega, ver Himmelmann (1964), ou recentemente Haug (2012, p. 503-529), especialmente p. 503-504.
} 
sua força; eles indicam sua forma única de lutar e sua astúcia; eles mascaram sua história ou, no caso de suas aparentemente insignificantes, mas raramente ausentes vestimentas (tecidas), destacam sua origem do mundo civilizado. ${ }^{31}$

Qualquer que seja o uso dado para a palavra "corpo" ao descrever imagens gregas, o argumento essencial da pesquisa deste artigo na relação entre figura e espaço e, de fato, mais especificamente na questão de "paisagem," como devemos ver, é que a figura humana não pode ser reduzida ao corpo em sua forma fisiológica. Em vez disso, ele vai além da unidade espacial de um torso, uma cabeça, dois braços e duas pernas. A figura é, ao mesmo tempo, um corpo definido e espaço compreendido ou, em outras palavras, não há dualismo fundamental entre figura e espaço nas pinturas em vasos áticos. Isso se prova mais crucial na questão da "paisagem." De fato, um elemento essencial (embora, obviamente, não o único) da estética das pinturas europeias de paisagens ${ }^{32}$ surge da tensão entre projeções ideológicas do homem, por um lado, capaz de ação, mas, em última instância, impotente e sujeito ao tempo, e seu ambiente natural, por outro, inalterável e infinito (ou até divino).

Esse dualismo está ausente no lekythos de Munique, do Pintor de Aquiles (fig. 2). Para dizer que a mulher está no Monte Helikon, como se eles fossem duas coisas distintas, uma figura e o espaço ao redor, não faria sentido: ao remover a figura da pintura, o "Monte Helikon" seria reduzido a uma linha fina e nada restaria para a inscrição toponímia descrever. ${ }^{33} \mathrm{O}$ "H $\mathrm{H} I K O N$ " denominado pela inscrição encontra substância somente na mulher sentada sobre a linha de relevo tocando cítara e, assim, comparada às musas do Helikon. É a figura da mulher tocando cítara que introduz o Helikon no lekythos, assim como é a figura de Dionysos que introduz a videira na ânfora de Boston (fig. 1). A capacidade das figuras, na cerâmica ática, de extrapolar os limites de seu corpo físico pode chegar tão longe a ponto de integrar a "paisagem" a representações de si mesmas.

Interessantemente, há uma correspondência entre a transgressão dos limites do corpo físico, como entidade especial bem definida pela figura, por um lado, e a limitação espacial de elementos da paisagem na pintura em vasos áticos, por outro. Alguns exemplos podem ilustrar isso. Pinturas do período Arcaico Tardio mostrando a punição de Sísifo representam a montanha onde ele foi condenado a carregar sua pedra como nada mais que uma coluna rochosa, como podemos ver em vários vasos áticos de figuras negras. ${ }^{34}$ Até o mar infinito

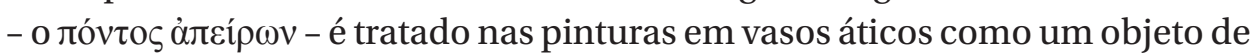

\footnotetext{
${ }^{31}$ Entre o grande número de estudos que lidam mais ou menos diretamente com esse tema e que não podem ser exaustivamente listados de qualquer modo, gostaria de mencionar somente a obra de Lissarrague mais diretamente ligada ao que foi dito aqui. Sobre a relação íntima e complexa entre heróis sozinhos e suas armas muito específicas, ou outros equipamentos na imagética de vasos áticos, ver especialmente Lissarrague (1980; 2007; 2008).

${ }^{32} \mathrm{~A}$ famosa tela do pintor romântico alemão Caspar David Friedrich, "Mönch am Meer (Moonrise Over The Sea)" pode ser um exemplo disso (e certamente bem extremo).

${ }^{33}$ Contra: Hedreen (2001, p. 183).

${ }^{34}$ Ver a ânfora do Pintor de Aqueloo em Munique (Antikensammlung 1549; ABV 383.12, Para 168; CVA Munique IX, pl. 12.3, 15.1-2, 17.5; ca. 510-500 a.C:; BA 302405). Sobre a punição de Sísifo nas pinturas em vasos áticos, ver LIMC VII, p. 783-784, Sísifo I 5-19 e Dietrich (2010, p. 35-37).
} 
expansão limitada, como exemplificado em uma ânfora em Mannheim onde um barco veleja literalmente num "segmento" de mar, inclinado até a linha do solo em ambos os lados (fig. 13). ${ }^{35}$ Em um skyphos de Nápoles, o solo rochoso sobre o qual Herácles reclina num banquete solitário não se expande além do corpo do herói (fig. 14) ${ }^{36}$ Em vez disso, o cenário permanence dentro da área e da dimensão espaciais da figura. O último exemplo aponta para a razão para esta prática: o solo rochoso sobre o qual Herácles reclina é parte integral da representação do herói, naquela situação anormal do banquete solitário, destacando uma perversão da instituição cultural da reunião coletiva, pela substituição da kliné manufaturada pela rocha "bruta". Como mero substituto da kliné, a rocha perde sua razão de ser em locais onde ela não sustenta o corpo do herói. Assim, ela não se expande mais, muito embora pode-se bem imaginar Herácles numa paisagem rochosa. Essa economia funcional do elemento paisagístico, estritamente ligada ao propósito a que ela se propõe para a respectiva figura, seja ela o barco todo ou um corpo único, é geralmente predominante (Dietrich 2010, p. 39-69, 327-365).

Um elemento essencial da estética das pinturas
europeias de paisagens surge da tensão entre projeções
ideológicas do homem, por um lado, capaz de ação, mas
impotente e sujeito ao tempo, e seu ambiente natural,
por outro, inalterável e infinito (ou até divino)

Resumindo, isso ocorre pelo fato de a figura poder se expandir além dos limites do corpo, ou seja, a representação do corpo não está limitada fisiologicamente pelo corpo. A transição entre o corpo, suas extensões e o contexto espacial é contínua. Embora só tenhamos observado até agora pinturas em vasos para chegar a essa conclusão, uma pessoa pode achar que isso seja verdade, com relação ao corpo na imagética grega dos períodos Arcaico e Clássico em geral. $\mathrm{O}$ crescente conhecimento sobre as diferenças do meio pictórico na atual metodologia arqueológica, porém, nos impede de tomar isso como regra geral. No entanto, uma observação sobre a escultura arquitetônica grega nos revela, de fato, que não lidamos aqui com uma característica específica das pinturas em vasos, mas que nesse suporte pictórico tão diferente, a dualidade moderna entre as figuras e seu contexto espacial está ausente quando nas pinturas em cerâmica.

${ }^{35}$ Reiss-Museum Cg 343; CVA Mannheim II, pl. 6-7; ca. 520-510 a.C.; BA 11. Sobre a representação do mar, ver Kunisch (1989, p. 64-70) e Dietrich (2010, p. 22-33).

${ }^{36}$ Nápoles, Museo Nazionale 81154; ABL 249.6; CVA Naples I, III.He 21, pl. 46.3-5; ca. $500-490$ a.C.; 306782. 


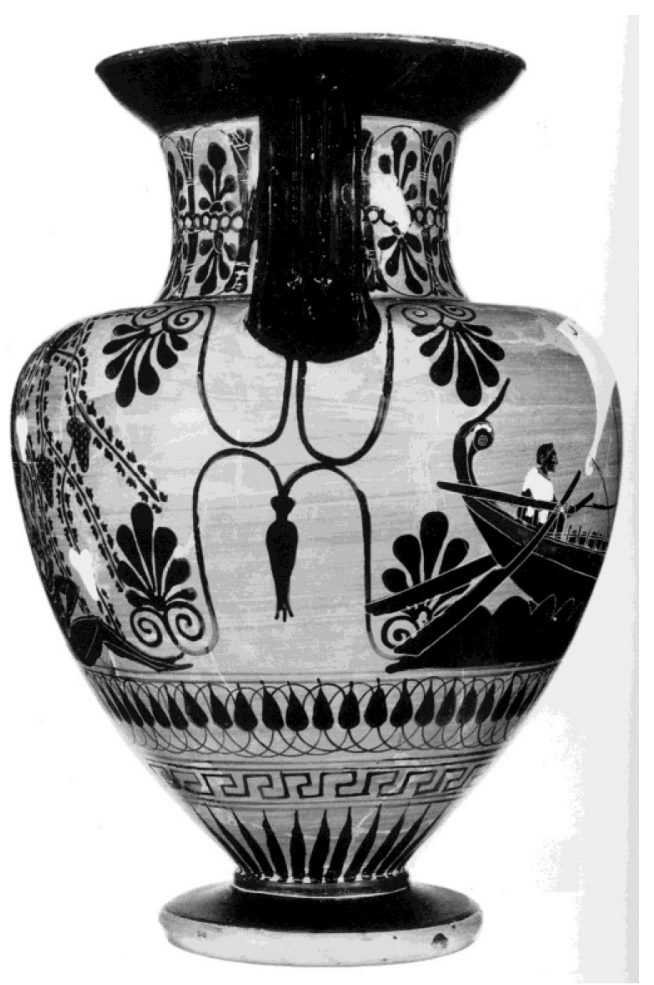

Figura 13 A: Ânfora ática de figura negras, ca. 520-510 a.C. (Reiss-Museum Cg 343), um barco navegando numa bem delimitada 'faixa d'água'.

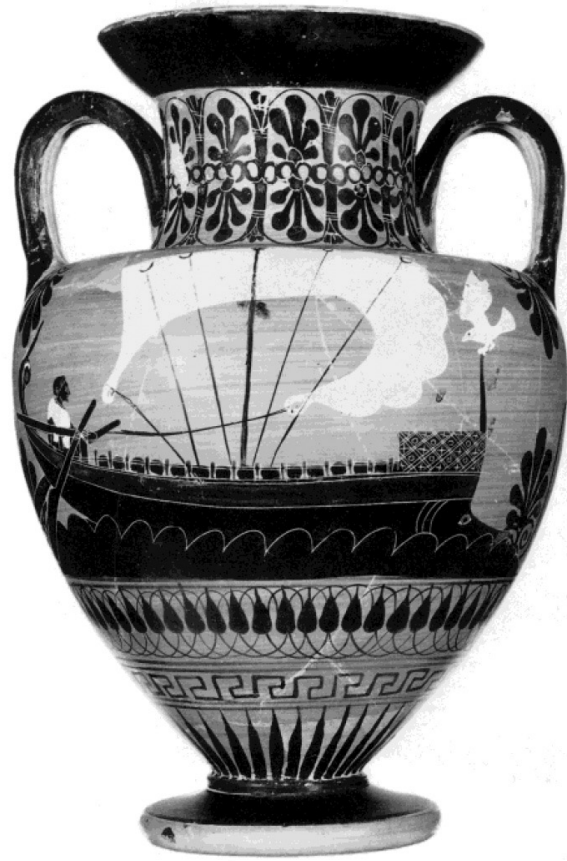

Figura 13 B 


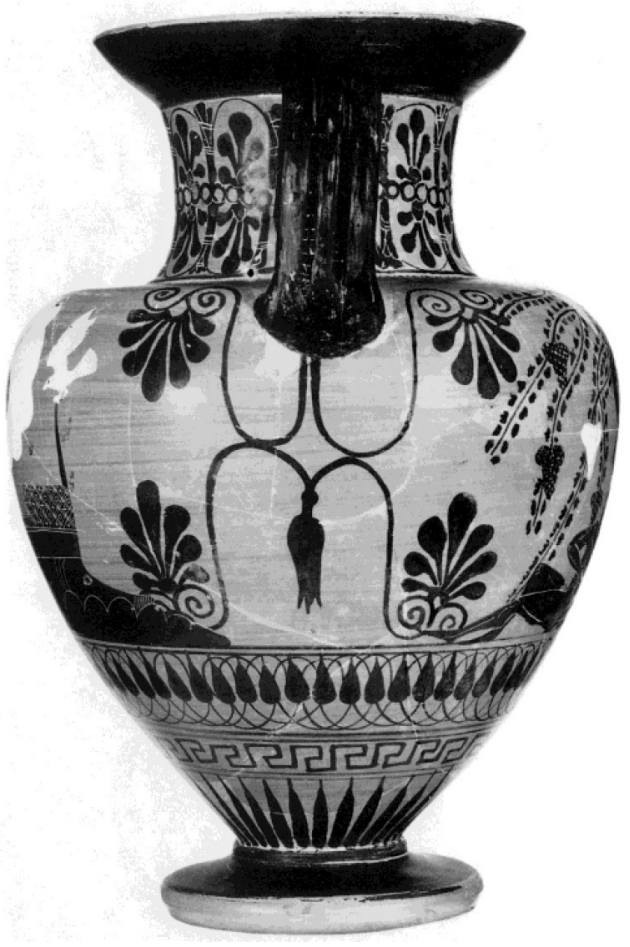

Figura $13 \mathrm{C}$

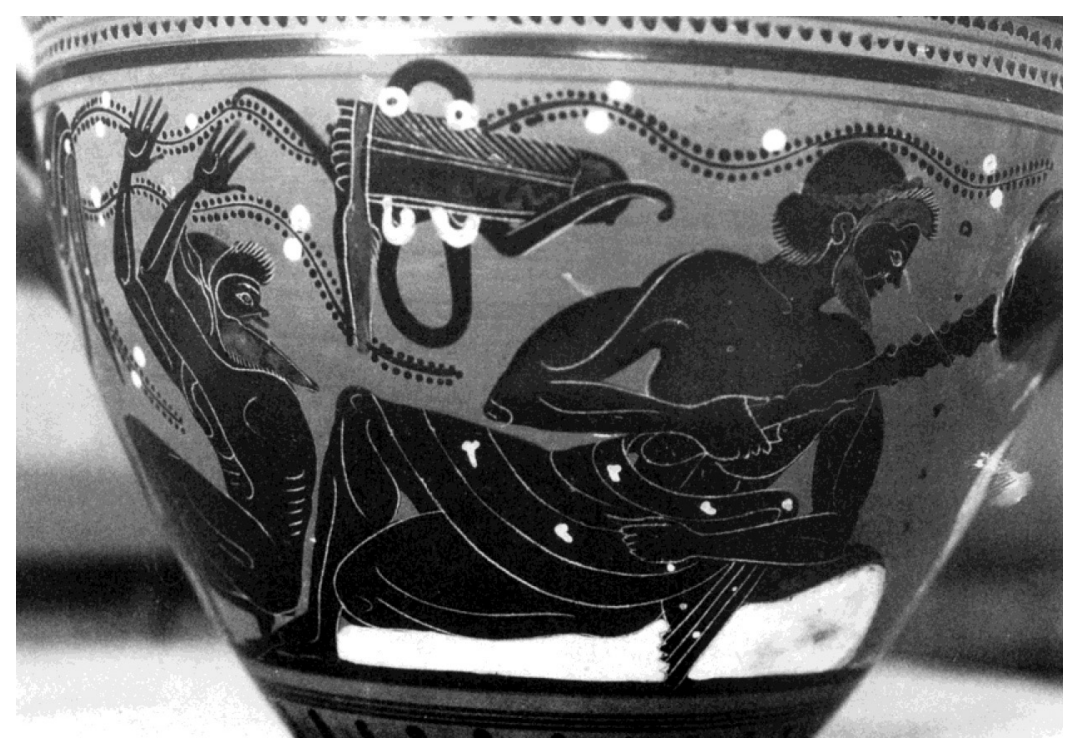

Figura 14: Skyphos ático de figuras negras, ca. 500-490 a.C. (Nápoles, Museo Nazionale 81154), com Herácles reclinando numa faixa de solo rochoso, bem demarcado ao comprimento de seu corpo. 


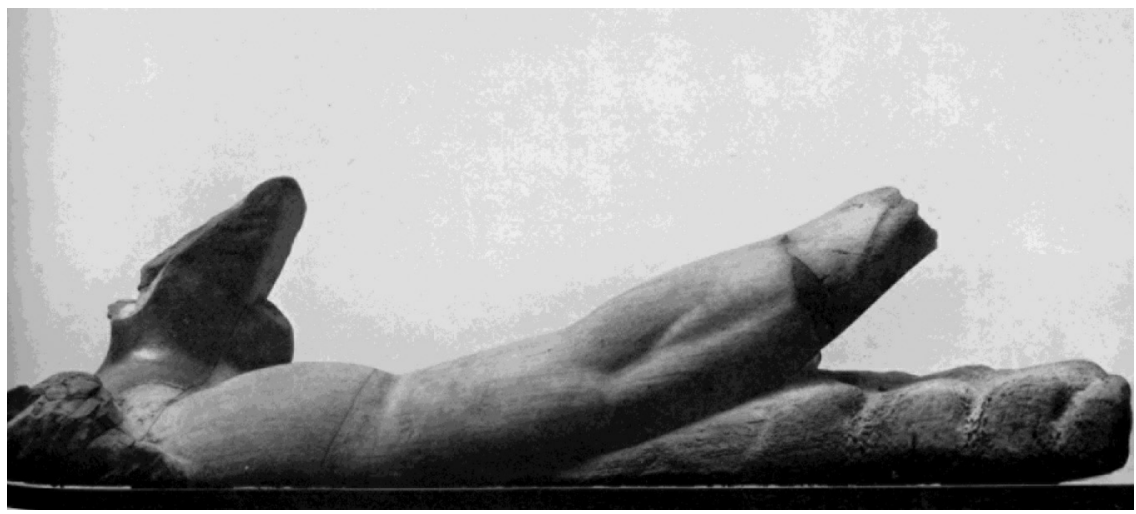

Figura 15A: Hélios emergindo do mar com sua carruagem, do canto esquerdo do frontão leste do Parthenon (Londres, British Museum).

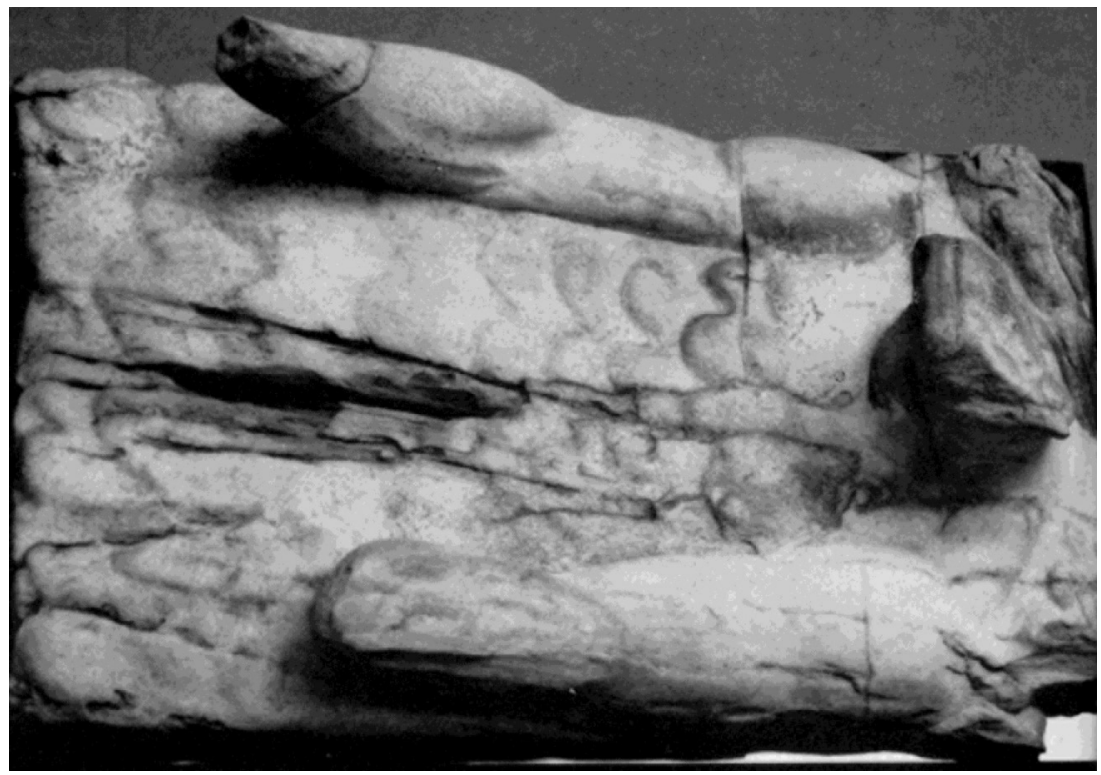

Figura 15 B

Isso é particularmente óbvio, por exemplo, na figura de Hélios emergindo do mar em sua carruagem, no canto esquerdo do frontispício leste do Parthenon (fig. 15) (Brommer, 1963, p. 3-4, 148; Palagia, 1993, p. 19; Erhardt, 2004). ${ }^{37}$ Somente as cabeças do deus e seus cavalos aparecem acima da superfície da água. O plinto da estátua está coberto com pequenas ondas, representadas de forma mais gráfica que plástica, indicando o mar de onde Hélios emerge. Essas ondas esquemáticas circulam a escultura, mas não se vão além do espaço que as cercam. O "mar" pode, assim, literalmente ser comparado ao plinto no qual se apoia a escultura, de forma bem semelhante ao que encontramos nas pintu-

\footnotetext{
${ }^{37} \mathrm{~A}$ bibliografia completa sobre esculturas do Parthenon é, obviamente, muito extensa e não pode ser resumida aqui. Para uma bibliografia concisamente comentada, ver Rolley (1999, p. 55-56) e Bol (2004, p. 509). A melhor apresentação de relíquias materiais de decoração escultural ainda são as publicações sistemáticas de Brommer (1963; 1967; 1977)
} 
ras em vasos áticos, com um barco navegando num "segmento de mar" claramente delimitado (fig. 13). ${ }^{38} \mathrm{O}$ elemento do cenário é uma parte da representação de Hélios e está intrinsecamente ligada a ele. Da mesma forma, outros elementos de paisagem encontrados na decoração escultural do Parthenon têm paralelos semelhantes nas pinturas em vasos áticos (Brommer, 1977, p. 100-101). Vamos tomar como exemplo o efebo controlando um touro bravo no friso do Parthenon (fig. 16) $\cdot^{39}$ A pequena pedra sobre a qual ele pisa, para se equilibrar melhor no chão, corresponde exatamente em forma e função à rocha na cena do touro de Maratona, na taça do mesmo período do Pintor de Kodros, representando os feitos de Teseu (fig. 17). ${ }^{40}$ Essa relação próxima com figuras nessa posição específica é típica para todas as inúmeras pedras que aparecem no friso do Parthenon. ${ }^{41}$ É o que encontramos na cena do touro contido, não porque essa cena em especial se passa num espaço mais rochoso, mas porque isso é necessário para a atitude específica do efebo: isso é parte da mise-en-scène de seu corpo em ação e não parte de um cenário independente. ${ }^{42}$ Mais enfaticamente, isso se aplica às pedras sobre as quais as figuras derrotadas em luta estão caindo - outra ocorrência típica de pedras (Dietrich 2010, p. 393-404), tanto em pinturas em vasos, quanto em escultura arquitetônica, como visto na métope sul 30 do Parthenon (fig. 18) (Brommer, 1967, p. 124-125; Ellinghaus, 2011, p. 55-56), ou em uma taça ática em Florença que aproximadamente pertence ao mesmo período (fig. 19). ${ }^{43}$ A pedra sobre a qual ele está caindo é parte integral, pode-se dizer, da materialização da figura agonizante.

Como regra geral, a tipologia morfológica e funcional das pedras, em sua grande correspondência com as necessidades e ações das figuras, é muito semelhante à decoração escultural da arquitetura e na decoração pintada dos vasos. Isso é visto de forma mais clara numa perspectiva diacrônica. Pedras no chão ainda são muito raras nas pinturas em vasos antes do fim do século VI a.C. Também não as encontramos na escultura arquitetônica. Quando pedras começam a aparecer no relevo arquitetônico, elas frequentemente traçam um paralelo muito próximo com as pinturas em vasos da mesma época. Esse é o caso da pedra sobre a qual Athená está sentada na métope de Olímpia, com

\footnotetext{
${ }^{38}$ Ver, por exemplo, Reiss-Museum Cg 343; CVA Mannheim II, pl. 6-7; ca. 520-510 a.C.; BA 11. Um lekythos contemporâneo em Berlin com a barca de Caronte "nadando em" - ou melhor "de pé" - sobre um "pedaço de água" retangular oferece um paralelo ainda mais aproximado (Antikensammlung F 2681; ARV 1385.2; CVA Berlin VIII, pl. 34 e fig. 7 (desenho); ca. 42O-410 a.C.; BA 217828. Ver Dietrich (2010, p. 26).

${ }^{39}$ Friso sul, placa XXXIX (ou XLIII). Sobre jovens refreando touros representados no friso do Parthenon, ver Jenkins (1994, p. 73) e Ellinghaus (2011, p. 125).

40British Museum E 84; ARV 1269.4; por volta de 440-420 a.C.; BA 217213. Sobre os elementos da paisagem dessa taça, ver Dietrich (2010, p. 416-419).

${ }^{4}$ Outras pedras aparecem particularmente (mas não somente) no friso oeste. Essas pedras estão fortemente ligadas às ações específicas das figuras, respondendo a algumas necessidades práticas de um local mais alto para colocar o pé. Ver, por exemplo, Jenkins (1994, p. 88, 106-107, 110-111).

${ }^{42}$ Para essa função das pedras e linhas de relevo nas pinturas ontemporâneas em vasos áticos, ver Dietrich (2010, p. 480-506). Uma interpretação diferente das pedras no friso do Parthenon é encontrada em Fehl (1961), interpretando as pedras como indicações topográficas. Para uma discussão sobre o tema, ver Jenkins (1994, p. 26-28).

43Museo Archeologico 3909; ARV 943.59, Para 432: pintor de Londres E 777; CVA Florença IV, III.I14-15, pl. 141; ca. $460-450$ a.C.; BA 212705.
} 
os pássaros do lago Estínfalo (fig. 20) (Hamiaux, 2001, p. 115-117). ${ }^{44}$ Pode-se encontrar a mesma morfologia peculiar das pedras regularmente em obras do mesmo período realizadas pelo pintor de Villa Giulia como, por exemplo, em uma hydria com Apolo e as musas no Vaticano (fig. 21) (Dietrich, 2010, p. 47-50). ${ }^{45}$ A morfologia dessas pedras é, obviamente, adequada para uma posição de sentar específica, com um braço para trás, apoiando o corpo, confirmando, assim, a norma de funcionalidade dos elementos da paisagem para as figuras representadas. Enquanto essas pedras isoladas são frequentemente encontradas nas pinturas em vasos áticos da primeira metade do século $\mathrm{V}$, um solo rochoso generalizado começa a aparecer somente na segunda metade do século $V^{46}$ É nessa mesma época que encontramos solo rochoso generalizado na escultura arquitetônica também como, por exemplo, nos frisos de Heféstion (Bockelberg, 1979; Rolley, 1999, p. 107, fig. 94-95; Knell, 1990, p. 127-139, fig. 209214), ou na cena da luta no friso oriental do Templo de Athená Nike, em Atenas (Rolley, 1999, p. 109-111; Knell, 1990, p. 140-149, fig. 222-224). Os vestígios de um grupo de frontispícios do período Clássico do Templo de Apolo Sosiano, em Roma, com uma amazonomaquia (batalha das amazonas) oferecem outro bom exemplo (La Rocca, 1985). Tanto nas pinturas em vasos quanto na escultura arquitetônica, esse solo irregular permite ao pintor diversificar as posições e atitudes das figuras e, assim, intensificar a tensão dramática das batalhas. ${ }^{47}$

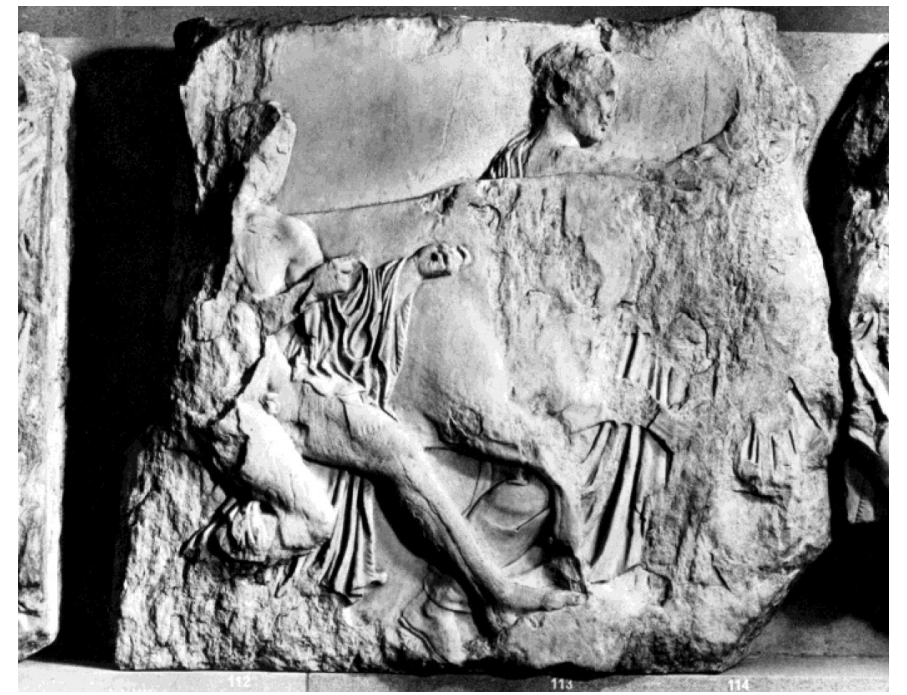

Figura 16: Jovem ateniense contendo um touro no cortejo de sacrifício, presente no friso sul do Parthenon (placa XXXIX - Londres, British Museum). Ao fazer isso, ele pisa com um pé numa pequena elevação rochosa.

\footnotetext{
${ }^{44} \mathrm{~A}$ maior parte dessa terceira métope ocidental (com a pedra) está agora no Louvre (inv. Ma 171a-c). Para uma discussão recente sobre decoração escultural do Templo de Zeus como um todo, ver Kaminski (2004), com bibliografia mais extensa em p. 500-501.

${ }^{45}$ Museo Gregoriano Etrusco 16506; ARV 623.70; ca. 460-450 a.C:; BA 207224.

${ }^{46}$ Ver, por exemplo, um dinos com uma amazonomaquia em Londres (British Museum 1899.7-21.5; ARV 1052.29: grupo do pintor Polignoto; CVA Londres VI, III.Ic.11, pl. 103.1a-d; ca. 440-430 a.C.; BA 213658). Tais representações de solo rochoso, entretanto, ainda são muito raras em pinturas em vaso. Em vez disso, pintores de vaso preferem usar linhas de relevo, com o objetivo de posicionar figuras em solo irregular. ${ }^{47} \mathrm{Um}$ bom exemplo disso na pintura de vasos áticos é o lekythos do pintor de Erétria em Nova York (Metropolitan Museum 31.11.13; ARV 1248.9, 1688, Para 469; ca. 420 a.C.; BA 216945. Ver fotos em Richter, (1936)
} 


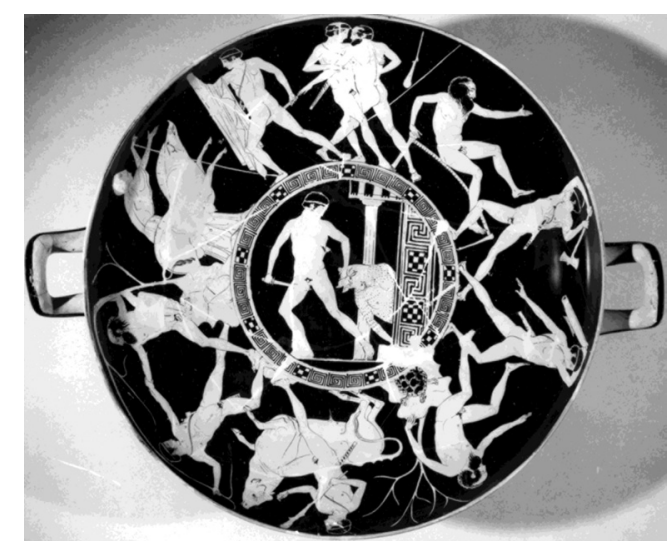

Figura 17: Taça ática de figuras vermelhas, ca. 440-420 a.C. (Londres, British Museum E 84) com os feitos de Teseu. A postura do herói, com um pé sobre a pedra na cena do touro de Maratona, corresponde fielmente à fig. 16.

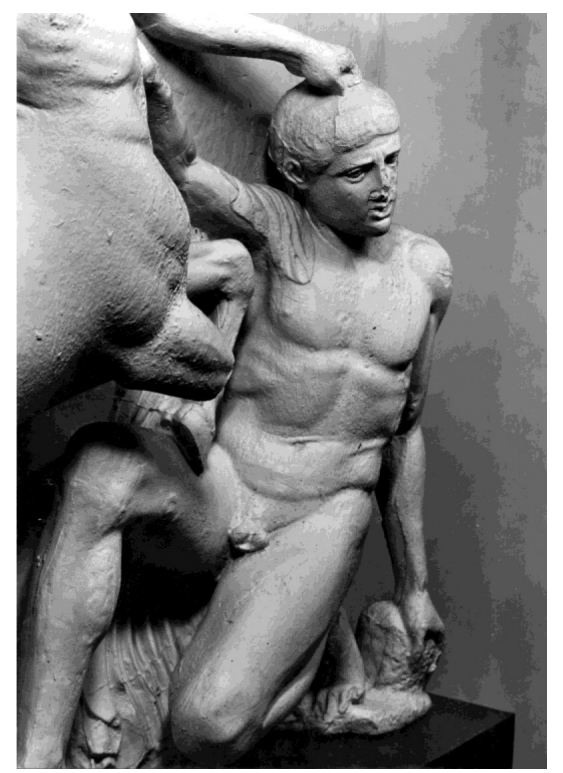

Figura 18: Métopa do Parthenon (Sul XXX - Londres, British Museum, em molde de gesso) com um centauro e um lápita, com a inicial minúscula lutando. O lápita cai sobre uma pequena pedra.

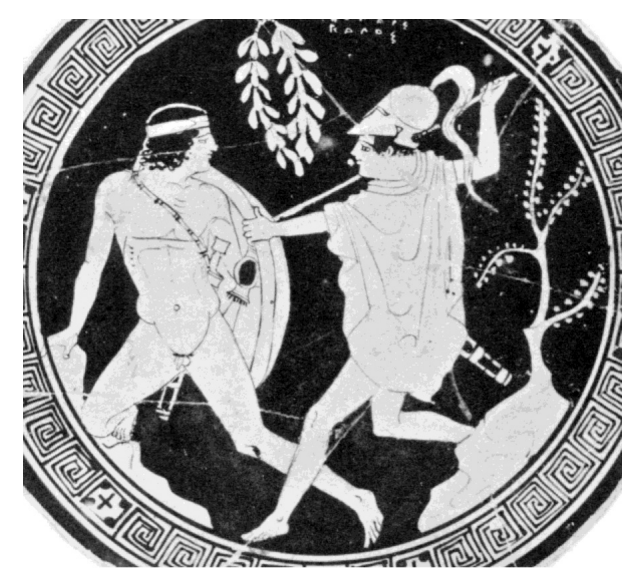

Figura 19: Medalhão de uma taça ática de figuras vermelhas, ca. 460-450 a.C. (Florença, Museo Archeologico 3909), com guerreiros lutando. Exatamente como na fig. 18, o derrotado cai sobre uma pedra. 


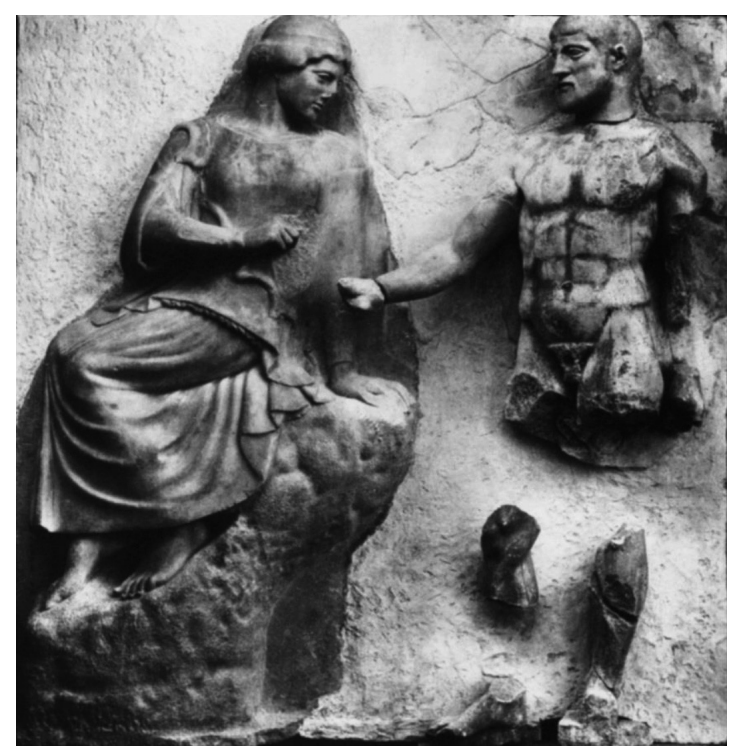

Figura 20: Métope de Olímpia Leste III (molde de gesso); Herácles entrega pássaros do lago Estínfalo a Athená, sentada numa pedra. Sua forma peculiar tem fortes paralelos nas pinturas em vasos áticos da mesma época.

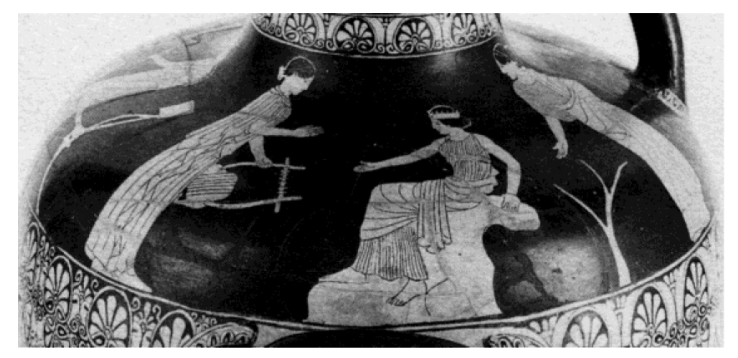

Figura 21: Hydria ática de figuras vermelhas, ca. 460-450 a.C. (Museo Gregoriano Etrusco 16506), com Apolo e as musas. Uma está sentada sobre uma pedra muito semelhante à pedra na métope de Olímpia Leste III (fig. 20).

Não há dúvida de que esse desenvolvimento das representações de elementos da paisagem relativo às figuras aconteceu simultaneamente nas pinturas em vasos áticos e na escultura arquitetônica. Esse é um fato notável. $\mathrm{Na}$ arte europeia pós-renascentista, qualquer tentativa de traçar um paralelo entre a representação da paisagem na escultura e na pintura seria absurda. Com relação à representação da paisagem, a pintura de paineis como representação de espaços (com ou sem figuras) excederia a escultura como representação isolada da figura (no espaço) de qualquer modo. Essa lógica intrínseca do suporte não se aplica à Grécia arcaica e clássica. Isto posto, devemos enfatizar aqui que pinturas em vasos não são totalmente equivalentes à pintura de paineis, nem a escultura arquitetônica (em sua maioria de relevos) equivale à escultura de vulto. Observar a eficácia deste paralelo com a escultura de vulto do século $\mathrm{V}$ a.C. é consideravelmente mais complicado que fazê-lo com a escultura arquitetônica. A principal razão para tanto é que a maior 
parte de nosso conhecimento sobre escultura clássica de vulto grega vem de cópias romanas, e é exatamente com objetos cercando a figura, como troncos de árvore ou pedras, que essas cópias são menos fidedignas. ${ }^{48}$ Essa dificuldade metodológica ligada à estrutura da evidência arqueológica disponível não pode, entretanto, invalidar nosso argumento. De fato, contrastando com o relevo bem mais "pintado" da Renascença, há tempos tem sido observado que a escultura de relevo pré-Helenística, essencialmente restrita à representação de figuras interagindo, é muito mais parecida com a escultura de vulto do que com a pintura de paineis. No caso de frontispícios, ambas as opções de decoração escultural - relevo e escultura de vulto - existem lado a lado: o primeiro sendo escolhido para esculturas menores e o último para esculturas maiores. Esse é um reflexo direto da equivalência básica de relevo-escultura e escultura. Dessa forma, nossas observações sobre esculturas de relevo arquitetônico provavelmente oferecerão uma aproximação razoavelmente boa do que poderíamos prever sobre a relação entre figura e espaço, para escultura clássica como um todo.

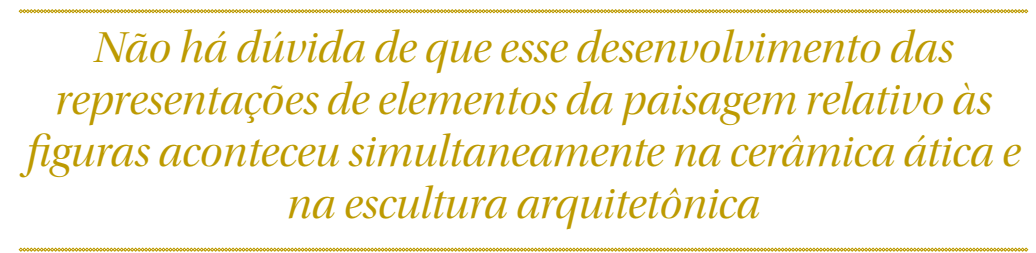

O que fazer com este surpreendente paralelo entre dois suportes pictóricos tão diferentes: pinturas em vasos e esculturas? O que poderia ser chamado de espacialidade da figura, capaz de conter elementos da paisagem, se aplica tanto à figura de Hélios do frontispício leste do Parthenon, contendo o mar do qual o deus emerge, quanto à de Dionysos na ânfora de Boston, que inclui as vinhas que o cercam. Isso obviamente sugere que a inclusão de elementos da paisagem na representação da figura pertence a um conceito de imagem mais geral, culturalmente determinado, aplicado a qualquer suporte pictórico. Em outras palavras, a espacialidade da figura pertence a uma antropologia de imagem específica, Arcaica e Clássica grega. Explorarei esse tema mais detalhadamente no fim deste artigo. Enquanto isso, porém, após longo estudo de uma questão que parecia óbvia, de compreender o que uma figura é, farei um estudo (mais breve) da questão complementar de saber o que seria o espaço pictórico.

\footnotetext{
${ }_{48}$ Tais objetos foram, de fato, frequentemente adicionados como apoio estrutural às figuras pelos escultores romanos, que copiaram estátuas de bronze em mármore, muito mais frágil. Assim, onde encontramos esses objetos rodeando as figuras em cópias romanas de originais gregos, não sabemos se elas foram adicionadas por quem as copiou ou se elas já existiam nos originais.
} 


\section{O que é espaço pictórico?}

Ao discutir espaço na escultura arquitetônica, seria absurdo referir exclusivamente à espacialidade da figura descrita até hoje, por exemplo, como espaço incluído como parte das figuras. Na verdade, para Hélios discutido acima (fig. 15), existe outro espaço muito mais aparente e mais determinante da estrutura geral da pintura. Esse é o espaço material da moldura arquitetônica. Se o espaço do triângulo plano do frontispício, desfavoravelmente adaptado à decoração figurada, não tivesse sido imposto às figuras, o deus Hélios nunca teria sido representado dessa maneira tão extrema, somente com sua cabeça e ombros emergindo do mar. ${ }^{49}$ Qual, então, é a relação entre o espaço material do triângulo do frontispício, externamente aplicado sobre as figuras, e o espaço incluído na representação da figura, como o mar de Hélios ou o Monte Olimpo na cena central do nascimento de Athená?

Antes de começar a complicar o problema, uma simples afirmação inicial pode ser feita com toda certeza: apesar das consequências bastante imediatas que a inconveniente moldura do triângulo plano do frontispício ${ }^{50}$ tem sobre a estrutura e na composição da cena figurada dentro dele, esse espaço material aplicado externamente não tem nenhum significado iconográfico intrínseco. $\mathrm{O}(\mathrm{s})$ escultor(es) não tentou expressar que o nascimento de Athená aconteceu no frontispício do templo; em vez disso, tentou incluir a cena de maneira mais convincente na moldura "impossível" do frontispício do templo.

O ponto crucial aqui é que essa estrutura material, embora sem qualquer valor icônico - Hélios emerge do mar e não do entablamento do templo - não é, contudo, de forma alguma irrelevante para a imagem, nem é ignorada pelas figuras em suas ações. Vou me explicar melhor. Uma paisagem de Claude Lorrain pode continuar além da moldura da tela, como se o espaço material do quadro não existisse. $\mathrm{O}$ espaço pictórico da paisagem pintada e a moldura material têm status ontológicos diferenciados. Até mesmo onde a tela pintada e sua moldura de madeira se tocam, não há nenhum ponto de contato entre o espaço pictórico da paisagem e sua moldura/espaço material. No caso do frontispício do Parthenon, a relação entre a cena figurada e seu espaço material é inerentemente diferente. Isso é visto de forma melhor no canto oposto do mesmo frontispício, onde a carruagem de Selene afunda no mar (fig. 22) (Brommer, 1963, p. 22-26, 156-157). Um de seus cavalos vira a cabeça para a direita, de forma a se projetar levemente para fora do triângulo anexo do frontispício e - mais notoriamente - de modo a alcançar com seu focinho bem visivelmente sob o nível da base da fachada. Pela lógica do espaço pictórico, seu focinho não deveria ser visível abaixo do nível do solo. A simples razão pela qual, neste caso, o focinho continua visível até a ponta de seu nariz é que o obstáculo material da base do frontispício não está lá. Assim, em contraste com a pintura em perspectiva da pós-Renascença, com seu espaço pictórico

\footnotetext{
${ }^{49} \mathrm{~A}$ propósito, onde a figura de Hélios aparece na moldura retangular mais conveniente do métope leste 14 do Parthenon, o corpo do deus está completamente representado. Sobre essa métope, ver o trabalho mais recente de Schwab (2009).

50“Essa fachada é uma forma infeliz de forçar a escultura da figura” (Boardman, 1978, p. 152).
} 
infinito "incluído" na limitada moldura material da pintura, o "solo" nessa pintura não se estende virtualmente além da moldura. Em vez disso, o "solo" corresponde exatamente à superfície que o frontispício oferece para a disposição das figuras. A moldura material do frontispício e o espaço das figuras são simplesmente idênticos.

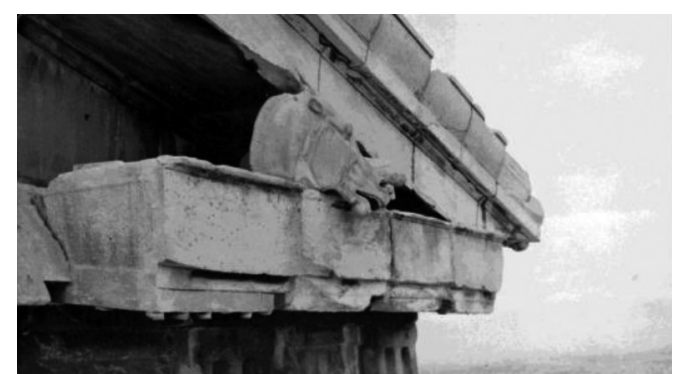

Figura 22A: Cabeça de um dos cavalos de Selene afundando no mar no canto direito do frontispício leste do Parthenon (Londres, British Museum AN 254914). Embora devessem corresponder ao "nível do mar," os focinhos dos cavalos chegam visivelmente abaixo do nível da base do frontispício.

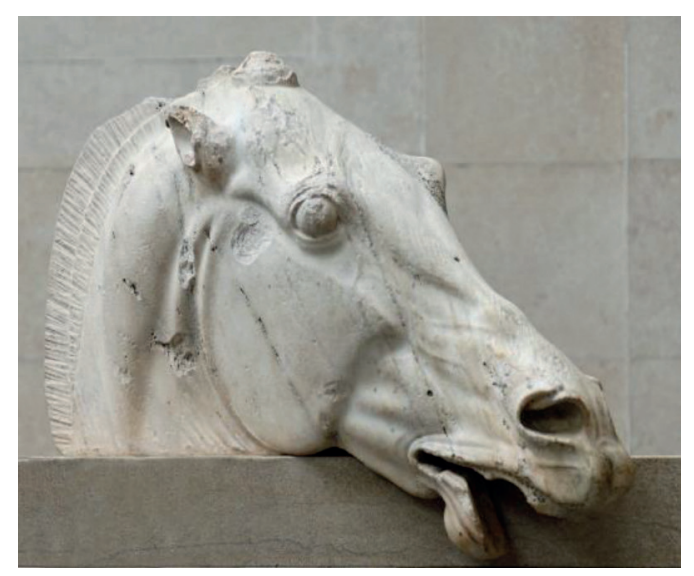

Figura 22 B

O Templo de Afaia em Egina oferece um exemplo perfeito do espaço material e do espaço da figura como idênticos. O guerreiro moribundo no canto esquerdo do frontispício leste, que tenta em vão se levantar novamente, está a ponto de, literalmente, cair para fora da moldura arquitetônica (fig. 23) (Ohly, 1976, p. 111-113; Dietrich, 2010, p. 125-126). Ao simular a queda iminente do guerreiro derrotado do triângulo do frontispício, o escultor usa a elevada posição das figuras do frontispício para fins figurativos. Outro exemplo que leva em consideração diretamente a posição das figuras na arquitetura decorada a fim de aumentar o poder dramático da pintura é o basileos estoa real na ágora ateniense. Como nos informa Pausânias, a luta entre Teseu e Skiron e a abdução de Céfalos pela deusa alada Eos (Aurora), decorada no telhado dessa arquitetura do início do século $\mathrm{V}$, como acrotérios em ambos os lados: Teseu joga Skiron do alto deste telhado, da mesma forma como ele o jogou do penhasco no relato mitológico, e Eos segura o lindo Céfalos para o alto, acima do espectador, ao levá-lo em voo pelos céus (Camp, 1986, p. 51-54; Camp; Mauzy, 2009, 
p. 17-18). ${ }^{51} \mathrm{O}$ Atlas Métope do Templo de Zeus em Olímpia revela uma forma diferente de usar o contexto arquitetônico (não-figurativo) para fins figurativos (fig. 24) (Kaminski, 2004, fig. 44a). ${ }^{52}$ A abóbada do céu que Herácles carrega em seus ombros é substanciada pelo teto do templo. Um teto de mármore é realmente muito pesado e, neste sentido, um substituto mais que eficiente para a abóbada do céu. O escultor, no entanto, não tentou fazer o espectador acreditar que esse teto realmente é a abóbada do céu! Ele não visualiza o episódio mitológico ao transpor virtualmente as figuras para a paisagem do Monte Atlas. Nós poderíamos, em vez disso, dizer que o escultor efetivou a ação de Héracles no espaço arquitetônico (e não figurativo) do templo. $\mathrm{O}$ fato de Héracles estar de pé na métope do templo deve, então, ser interpretado literalmente: essa não é somente uma representação correta do templo como uma arquitetura decorada, mas também uma descrição válida da cena! Não existe aqui um espaço pictórico que destacaria as figuras de seu espaço material.

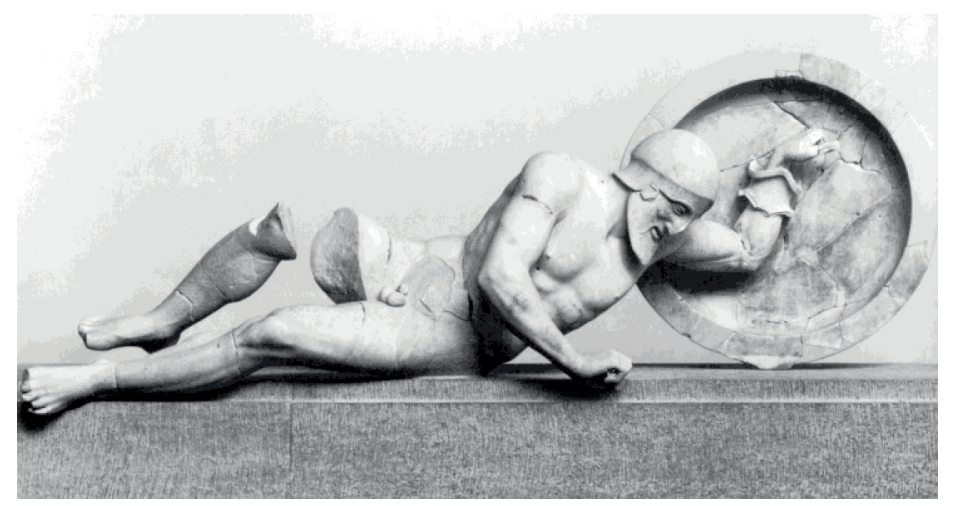

Figura 23: Figura do canto esquerdo do frontispício leste do Templo de Afaia em Égina (Munique, Glyptothek). Ao tentar em vão se levanter novamente, o guerreiro moribundo está, literalmente, quase caindo do triângulo do frontispício.

Voltando à nossa questão inicial de conhecer a exata natureza da relação entre o (espaço do) mar, de onde Hélios emerge no Parthenon, e o (espaço do) frontispício de onde ele emerge (fig. 15), há uma resposta clara. Hélios aparece na base do frontispício. E esses blocos de mármore não perpassam o processo da metamorfose figurativa que os transformaria no mar. Eles permanecem o que são: parte do frontispício do templo. De modo correspondente, o evento que acontece naquele frontispício também permanence o que é: Hélios emergindo do oceano, a representação do mar incluída na figura do próprio deus. O espaço pictórico da imagem é idêntico ao da moldura arquitetônica, o que não lhe concede, entretanto, nenhum significado iconográfico. Simplificando: não há nenhum espaço pictórico intermediando as figuras e sua moldura material.

51Ver Pausânias 1.3.1-2

52Para mais literatura sobre o Templo de Zeus, ver acima nota 51. Para uma interessante discussão sobre essa métope no contexto de fenômenos semelhantes nas pinturas em vasos, ver Martens (1992, p. 45-55). 


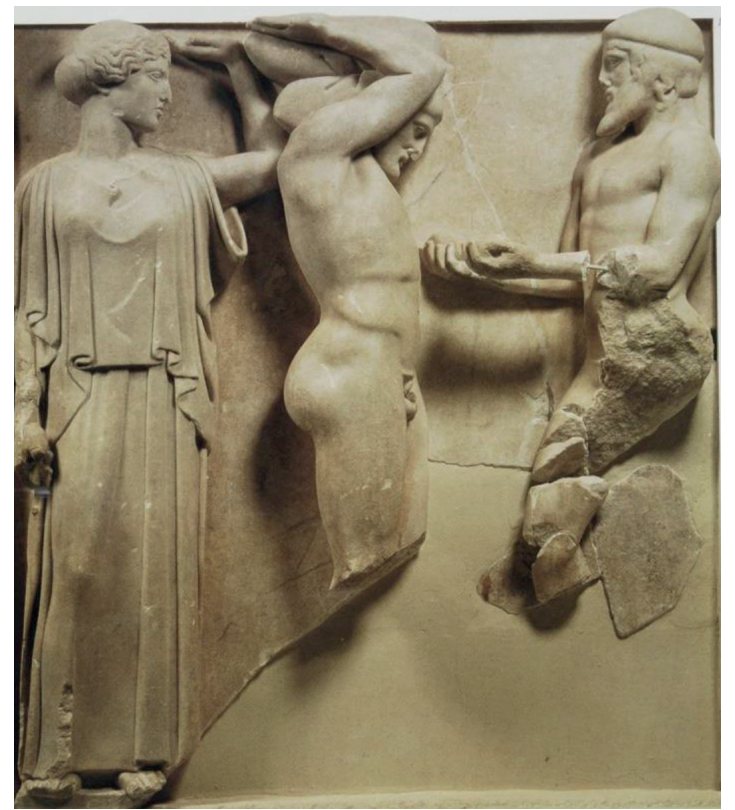

Figura 24: Métope leste IV de Olímpia (modelo de gesso); Atlas traz as maçãs das Hespérides para Héracles, que está segurando o firmamento com a ajuda de Atena. O teto de mármore do templo funciona como substituto do firmamento.

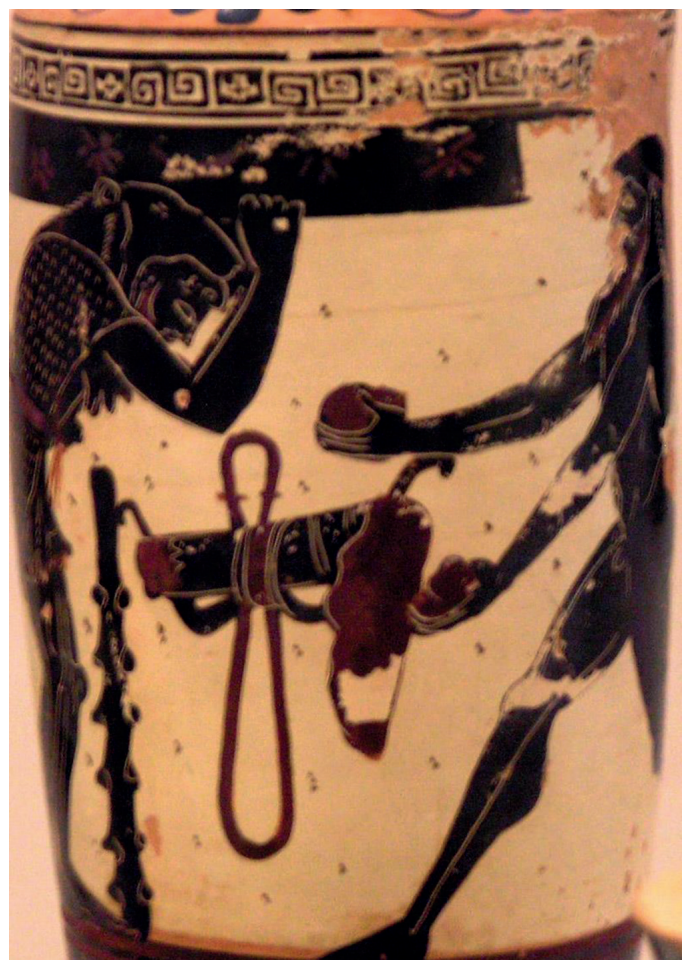

Figura 25: Lekythos ático de figuras negras, ca. $490-480$ a.C. (Atenas, National Museum 1132), com Héracles e Atlas. Assim como na métope de Olímpia, o "teto" da área pintada funciona como substituto para a abóbada do céu. Estrelas foram pintadas na arquitrave que Héracles segura.

Sobre essa conceituação de espaço, a escultura arquitetônica oferece um bom modelo para descrever a relação das figuras com suas molduras materiais 
também nas pinturas em vasos (Dietrich, 2010, p. 114-137). No lekythos do Pintor de Athená , Héracles segura uma arquitrave coberta de estrelas, como substituta para a abóbada do céu (fig. 25) ${ }^{53}$ Essa representação da história de Atlas, portanto, acompanha a mesma ideia da métope de Olímpia: a área pintada do lekythos é interpretada como moldura arquitetônica, cujo "teto" é sustentado por Héracles. É fácil encontrar nas pinturas de vasos áticos outros exemplos para apoiar essa leitura arquitetônica de recipientes decorados. ${ }^{54}$ Frequentemente, molduras pintadas na área da pintura são interpretadas como paredes sólidas como, por exemplo, na famosa ânfora de Exéquias no Vaticano, onde as armas do herói estão apoiadas na borda da área da pintura. ${ }^{55}$ No entanto, essas "paredes" laterais não têm nenhum significado iconográfico, a menos que assumíssemos que Aquiles e Ajax jogam o dado dentro de uma caixa fechada. O mesmo é verdade no caso do lekythos: o trabalho de Héracles consiste em sustentar a abóbada do céu e não a aba do vaso - mas esse trabalho é efetivado no espaço que o lekythos concede às figuras. Até mesmo para o guerreiro agonizante, que está caindo do triângulo do frontispício do Templo de Afaia, encontramos um paralelo direto nas pinturas em vasos áticos. Numa cratera de meados do século $\mathrm{V}$ com uma amazonomaquia, uma amazona ferida mortalmente por uma lança grega parece quase cair fora da área da pintura, como se ela tivesse dado um passo em falso e "perdido" a linha base da área da pintura (fig. 26). ${ }^{56}$ Este vaso ganha outra dimensão quando o pintor faz uso das linhas de relevo, quebrando, assim, a ligação (previamente) necessária das figuras com a linha base da pintura. Alguém pode achar que este detacamento da linha base concorreria com o destacamento da moldura material do vaso, e resulta no surgimento do conceito de um espaço pictórico autônomo. No entanto, o fato das figuras poderem ainda literalmente "cair para fora da imagem" mostra que aquela área de pintura permanece um espaço essentialmente finito, definido e delimitado pela arquitetura do vaso. Neste caso, a área de pintura do vaso é perfeitamente comparável à métope, frontispício ou friso esculpidos na arquitetura monumental.

\footnotetext{
${ }^{53}$ Atenas, National Museum 1132; ABV 522, ABL 256.50; ca. 490-480 a.C.; BA 330739. Ver sobre esse lekythos na obra de Dietrich (2010, p. 581, nota 191).

${ }^{54}$ Outro caso óbvio onde a aba de um lekythos funciona como teto da área da pintura é um com Pholus e outro centauro de pé ladeando um pithos (Palermo, Collezione Mormino 676; CVA Palermo, Collezione Mormino I, III.H.7, pl. 8.2-4; começo do século V a.C. (pintor de Gela); BA 3050). Três colunas sustentam o limite superior da área da pintura, como se fosse um pedaço do entablamento - e essas colunas não têm, claro, nada a ver com a caverna de Pholus, onde o pithos para vinho está. Para mais detalhes, ver Dietrich (2010, p. 103-104).

${ }^{55}$ Museo Gregoriano Etrusco 16757; ABV 145.13, 672.3, 686, Para 60: Exéquias; ca. 540 a.C:; BA 310395. Sobre essa representação e outras semelhantes de objetos se apoiando sobre "paredes laterais" da área da pintura, ver Dietrich (2010, p. 115-119).

56Metropolitan Museum 07.286.84; ARV 613.1, 1662, Para 397: Pintor dos sátiros lanosos; ca. 450 a.C.; BA 207099 .
} 


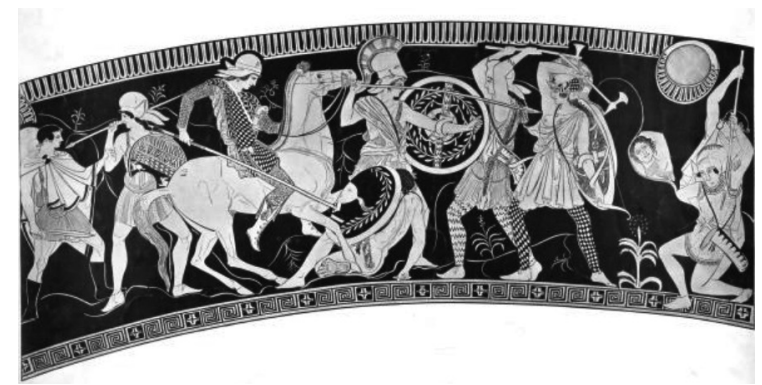

Figura 26: Cratera ática de figuras vermelhas, ca. 450 a.C. (Metropolitan Museum 07.286.84), com uma amazonomaquia. Uma amazona mortalmente ferida por uma lança grega está quase caindo para fora da área da pintura, assim como o guerreiro agonizante no frontispício leste de Egina (fig. 23)

\section{Conclusão}

Nas duas partes deste artigo, os aparentemente evidentes conceitos complementares de figura e espaço pictóricos se submeteram a uma pesquisa crítica. Abordei consecutivamente os dois suportes pictóricos mais bem preservados em nosso registro material da cultura grega dos séculos VI e V: a pintura em vasos áticos e a escultura arquitetônica. Ao contrário do que se poderia esperar desses dois suportes diferentes, várias analogias prevaleceram. Em ambos os casos, a figura abrange mais que o corpo em sua definição fisiológica. Seja pela idumentária, pela armadura ou pelos atributos nas mãos da figura ou mostrados na área da pintura, o corpo pode ser estendido além de seus limites presumidos. ${ }^{57}$ Nenhuma oposição categórica como a que há entre objeto (contido) e espaço (contendo) existe entre a figura e o espaço que a cerca. Em vez disso, há uma contínua transição. De fato, o espaço ao redor pode até ser uma parte intrínseca da figura. Como no caso de Dionysos na pintura em vasos áticos do período Arcaico Tardio, cercado por videiras, que literalmente se originam e crescem de seu corpo, ou como no caso de Hélios emergindo no frontispício leste do Parthenon, onde o mar é parte intrínseca da figura.

Para essa dimensão espacial da figura, capaz de imprimir "seu" espaço no que a cerca na área da pintura, corresponde a qualidade não-figurativa do espaço da pintura como um todo. O cerne material da pintura não se anula em favor de um espaço pictórico ilusionista. A metamorfose figurativa, que transforma o padrão pintado no vaso ou o mármore esculpido no templo em uma figura, não ocorre na moldura material da pintura: o triângulo do frontispício continua sendo um triângulo do frontispício. Pode-se contestar que o mesmo seja verdade para a moldura de uma tela. O que faz a diferença crucial aqui é

\footnotetext{
${ }^{57}$ A transgressão dos limites fisiológcos do corpo e a inclusão de roupas e atributos em sua representação pictórica pode ser relevante para a história do corpo, um tema proeminente em estudos mais recentes. Particularmente, isso poderia nos ajudar a repensar algumas premissas básicas sobre nudez, tal como a antítese padrão da nudez masculina em oposição ao vestiário feminino (ver, por exemplo, a recente obra de Haug [2012, p. 504-511], com muitas observações importantes sobre a distinção original entre nudez e idumentária, embora com uma interpretação diferente), ou a nudez grega, em oposição ao vestuário romano (ver, por exemplo, as interessantes, porém dicotômicas, observações de Meister [2012, p. 23-27, 47-51]; para uma discussão sobre nudez grega e vestuário romano mais focada na ambiguidade, ver Squire [2013]).
} 
que, em contraste com a moldura da tela, as características do enquadramento da área da pintura em vasos áticos ou na escultura arquitetônica se mantêm ao alcance das figuras. Objetos podem se apoiar sobre as "paredes" laterais da área de pintura do vaso pintado. Héracles pode segurar o "teto" da métope, em vez da abóbada do céu. Figuras podem até, literalmente, cair para fora da área de pintura. As figuras estão posicionadas e agem dentro de seu espaço material, não-figurativo, sem a mediação do espaço pictórico. Elas estão literalmente "no vaso," "na métope," "no friso" ou "no frontispício."

Um estudo paralelo do suporte pictórico de vasos áticos decorados e do meio escultural na decoração figural da arquitetura monumental revelou uma analogia essencial na relação entre figura e espaço. O que devemos fazer com esse resultado? Deveria estar claro que isso não completamente descarta a possibilidade da diferença provocada pelo suporte. Não há dúvida de que um estudo com outro foco poderia ter apontado diferenças na interpretação de elementos de paisagem nos dois suportes pictóricos. Esse estudo mostra somente que colocar o foco unicamente nas diferenças no suporte pictórico teria impedido o reconhecimento dos princípios comuns encontrados aqui, com relação à figura e espaço em suportes diferentes. Analogias além da diferença de suporte argumentam, contudo, pela adoção de alguns pontos comuns nas muitas variedades de imagens gregas. Na verdade, é provável que essas analogias apontem para uma característica mais geral das imagens neste contexto histórico-cultural específico. O que foi descoberto tem a ver, afirmo, com uma determinação fundamental do que uma imagem foi na Grécia dos séculos VI e V a.C. Simplificando, isso pode ser formulado da seguinte maneira: a mímese pictórica não oferece uma visão das figuras num espaço ilusório distinto do espaço do espectador. Em vez disso, torna essas figuras presentes no espaço do espectador: no vaso, no templo ou - isso pode ser conjecturado para as estátuas eretas, uma categoria de imagens que não foi estudada aqui - no espaço público do santuário, da necrópole ou da ágora (Dietrich, 2010, p. 543-546, 551-553). ${ }^{58}$ Essa ênfase no poder de presentificação de imagens gregas não é, de forma alguma, algo novo. A teoria de Vernant da antiga imagem grega destacou essa característica básica, muito embora ele tenha baseado sua argumentação principalmente em textos antigos (Vernant, 1983). Na pesquisa atual, a afirmação geral de Vernant sobre imagens gregas desempenha um papel importante em pesquisas tão diferentes como a de Verity Platt, Facing the Gods (2011), ou os trabalhos mais recentes de Tonio Hölscher sobre a cultura visual grega (Hölscher, 2012, p. 19-44; 2009, p. 54-67). ${ }^{59}$ Seja como for, muito pouco já foi feito para substanciar essa afirmação sobre as imagens gregas através de um estudo profundo de pinturas singulares. Caso contrário, não se pode provar que esse seja um fator determinante em sua forma e padrões concretos.

\footnotetext{
58Uma frequente citação, exemplo paradigmático da presença real e agente da pessoa representada que aquela estátua antiga deve supostamente reproduzir é o caso da estátua de Teágenes de Tasos, erguida na ágora, e o episódio reportado por Pausânias (Pausânias, Descrição da Grécia, 6. 11. 5). Ver Hölscher (2010, p. 19). ${ }^{59} \mathrm{O}$ conceito de presentificação é, por exemplo, também crucial para Bielfeldt (2014). Ver particularmente a obra de T. Hölscher (2014) e F. Hölscher (2014).
} 
É este nível de especificidade com relação à imagem em um contexto histórico-cultural - ou, em outras palavras, uma certa determinação antropológica da imagem - que pode ser negligenciada quando focamos muito exclusivamente no suporte pictórico. A crescente conscientização do suporte como fator determinante foi certamente uma resposta justificada à ideia excessivamente totalizante de um período-estilo completamente abrangente, uma ideia que pautou a história da arte antiga (particularmente a alemã), pelo menos até os anos 70 . Isso também problematiza corretamente uma ligação muito limitada entre a produção de imagem e a história (política), como ainda amplamente encontrado em estudos atuais. ${ }^{60}$ Isso, porém, não deve nos impedir de adotar uma perspectiva entre-suportes da cultura visual grega antiga também, sobretudo porque as perspectivas suporte-específico e entre-suportes podem se beneficiar mutuamente e ressaltar a relevância de observações individuais. No presente estudo são as diferenças fundamentais na pintura em vasos e esculturas arquitetônicas como suportes de representação pictórica que fazem o fato dos princípios comuns pautarem os dois tipos de imagem algo tão memorável.

\section{Imagens}

Fig. 1

Título: ânfora ática de figuras negras, ca. 540 a.C. (Boston, Museum of Fine Arts 63.952), com Dionysos entre videiras.

Crédito: Munique, Museum für Abgüsse Klassischer Bildwerke, Photothek.

Fig. 2

Título: Lekythos ático de fundo branco, ca. 440 a.C. (Munique, Antikensammlung S 80), com mulher tocando cítara (uma musa?) e a inscrição " " (Helikon).

Crédito: Munique, Museum für Abgüsse Klassischer Bildwerke, Photothek.

Fig. 3

Título: Ânfora ática de figuras negras, ca. 520 a.C. (Roma, Villa Giulia 2609 (106463), com Dionysos entre videiras crescendo tanto da terra quanto de sua mão.

Crédito: Dietrich (2010, fig. 52).

Fig. 4

Título: Torso arcaico de um guerreiro com couraça, de Samos, ca. 520-510 a.C. (Berlin, Antikensammlung 1752)

Crédito: Berlin, Archäologische Sammlung des Winckelmann-Instituts, Photothek.

Fig. 5

Título: Torso de um arqueiro, com couraça totalmente 'fundida' ao corpo, da Acrópolis atenense (Atenas, Museu da Acrópolis 599), ca. 470 a.C.

Crédito: Berlin, Archäologische Sammlung des Winckelmann-Instituts, Photothek.

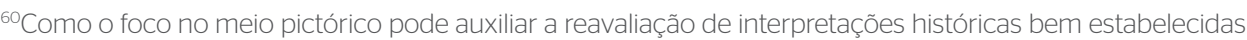
de iconografia é melhor exemplificado pela obra de Susanne Muth sobre violência nas pinturas de vasos áticos dos séculosVI e $\vee$ a.C. (ver particularmente a obra de Muth [2008], com uma crítica violenta e, na minha opinião, injustificada, de Christian Kunze em Bonner Jahrbücher 2010/2011, p. 595-602; e Muth [2006]).
} 
Fig. 6:

Título: Ânfora ática de figuras negras, ca. 520-500 a.C. (Rhodes, Museu Arqueológico 301637), com Héracles lutando com as Amazonas. A couraça da Amazona de joelhos é mostrada de perfil em sua parte inferior e sua parte superior de frente, como se ela fosse um adorno elástico, colado a seu corpo.

Crédito: Muth (2008, fig. 252).

Fig. 7

Título: Taça ática de figuras vermelhas do pintor Eufronios, ca. 510-500 a.C. (Munique, Antikensammlung 2620), Héracles lutando contra Gerião com a pele de leão duplicando sua cabeça.

Crédito: Wikimedia Commons (domínio público).

Fig. 8

Título: Ânfora ática de figuras negras, ca. 530-520 a.C. (Boston, Museum of Fine Arts 01.8027), a armadura de Aquiles.

Crédito: CVA Boston I, pl. 27.2.

Fig. 9

Título: Ânfora ática de figuras negras, ca. 520-500 a.C. (Munique, Antikensammlung 1557), Héracles e o leão, os atributos do herói estão espalhados por toda área da pintura.

Crédito: Wikimedia Commons (domínio público).

Fig. 10

Título: Taça ática de figuras negras com olho pintado, ca. 530-520 a.C. (Munique, Antikensammlung 2052), com mênade dançando e segurando vinhas.

Crédito: Dietrich (2010, fig. 189).

Fig. 11

Título: Ânfora ática de figuras negras, ca. 520-510 a.C. de Psiax (Madri, Museo Arqueologico Nacional 11008), Dionysos com sátiros, mênades e ramos de hera saindo da figura central do deus, se espalhando por toda área da pintura.

Crédito: Dietrich (2010, fig. 151).

Fig. 12

Título: Taça figuras negras, ca. 500-490 a.C. (Paris, Cabinet des Médailles 330), Aquiles perseguindo Troilo. Galhos reforçam o movimento e a ação pela direção de seu crescimento.

Crédito: Ridder (1902, fig. 41).

Fig. 13

Título: Ânfora ática de figura negras, ca. 520-510 a.C. (Reiss-Museum Cg 343), um barco navegando numa bem delimitada 'faixa d'água'.

Crédito: Dietrich (2010, fig. 1).

Fig. 14

Título: Skyphos ático de figuras negras, ca. 500-490 a.C. (Nápoles, Museo Nazionale 81154), com Herácles reclinando numa faixa de solo rochoso, bem demarcado ao comprimento de seu corpo. Crédito: Dietrich (2010, fig. 41).

Fig. 15

Título: Hélios emergindo do mar com sua carruagem, do canto esquerdo do frontão leste do Parthenon (Londres, British Museum).

Crédito: Brommer (1963, pl. 21 e 22.2).

Fig. 16

Título: Jovem ateniense contendo um touro no cortejo de sacrifício, presente no friso sul do Parthenon (placa XXXIX - Londres, British Museum). Ao fazer isso, ele pisa com um pé numa pequena elevação rochosa.

Crédito: Brommer (1963, pl. 154). 
Fig. 17

Título: Taça ática de figuras vermelhas, ca. 440-420 a.C. (Londres, British Museum E 84) com os feitos de Teseu. A postura do herói, com um pé sobre a pedra na cena do touro de Maratona, corresponde fielmente à fig. 16 .

Crédito: Dietrich (2010, fig. 347).

Fig. 18

Título: Métopa do Parthenon (Sul XXX - Londres, British Museum, em molde de gesso) com um centauro e um lápita lutando. O lápita derrotado cai sobre uma pequena pedra.

Crédito: Berlin, Archäologische Sammlung des Winckelmann-Instituts, Photothek.

Fig. 19

Título: Medalhão de uma taça ática figuras vermelhas, ca. 460-450 a.C. (Florença, Museo Archeologico 3909), com guerreiros lutando. Exatamente como na fig. 18, o derrotado cai sobre uma pedra.

Crédito: Dietrich (2010, fig. 337).

Fig. 20

Título: Métope de Olímpia Leste III (molde de gesso); Herácles entrega pássaros do lago Estínfalo a Athená, sentada numa pedra. Sua forma peculiar tem fortes paralelos nas pinturas em vasos áticos da mesma época.

Crédito: Berlin, Archäologische Sammlung des Winckelmann-Instituts, Photothek.

Fig. 21

Título: Hydria ática de figuras vermelhas, ca. 460-450 a.C. (Museo Gregoriano Etrusco 16506), com Apolo e as musas. Uma está sentada sobre uma pedra muito semelhante à pedra na métope de Olímpia Leste III (fig. 20).

Crédito: Dietrich (2010, fig. 396).

Fig. 22

Título: Cabeça de um dos cavalos de Selene afundando no mar no canto direito-do frontispício leste do Parthenon (Londres, British Museum AN 254914). Embora devessem corresponder ao "nível do mar," os focinhos dos cavalos chegam visivelmente abaixo do nível da base do frontispício. Crédito: Brommer (1963, pl. 60.1, fig. 22a) e Wikimedia Commons (domínio público).

Fig. 23

Título: Figura do canto esquerdo do frontispício leste do Templo de Afaia em Égina (Munique, Glyptothek). Ao tentar em vão se levanter novamente, o guerreiro moribundo está, literalmente, quase caindo do triângulo do frontispício.

Crédito: Ohly (1976, p. 111-113, pl. 64).

Fig. 24

Título: Métope leste IV de Olímpia (modelo de gesso); Atlas traz as maçãs das Hespérides para Héracles, que está segurando o firmamento com a ajuda de Atena. O teto de mármore do templo funciona como substituto do firmamento.

Crédito: Berlin, Archäologische Sammlung des Winckelmann-Instituts, Photothek.

Fig. 25

Título: Lekythos ático de figuras negras, ca. 490-480 a.C. (Atenas, National Museum 1132), com Héracles e Atlas. Assim como na métope de Olímpia, o "teto" da área pintada funciona como substituto para a abóbada do céu. Estrelas foram pintadas na arquitrave que Héracles segura. Crédito: Wikimedia Commons (domínio público).

Fig. 26

Título: Taça ática de figuras vermelhas, ca. 450 a.C. (Metropolitan Museum 07.286.84), com uma amazonomaquia. Uma Amazona mortalmente ferida por uma lança grega está quase caindo da pintura, assim como o guerreiro agonizante no frontispício leste de Egina. (fig. 23)

Crédito: Furtwängler; Reichold (1904-1932, pl. 116). 


\section{Referências bibliográficas}

BÉRARD, Claude et al. (ed.). La cité des images: religion et société en Grèce antique. Paris: F. Nathan, 1984.

BERNERT, Ernst; LORENZ, Irma. Naturgefühl. RE, v. 16, n. 32, 1933.

BIELFELDT, Ruth (ed.). Ding und Mensch in der Antike. Gegenwart und Vejagegenwärtigung. Akademiekonferenzen (Heidelberger Akademie der Wissenschaften), v. 16. Heidelberg: Winter, 2014. BLÜMEL, Carl. Die archaisch griechischen skulpturen der Staatlichen Museen zu Berlin. Berlin: Akademie-Verlag, 1963.

BOARDMAN, John. Greek sculpture: the archaic period. Londres: Thames e Hudson, 1978.

BOARDMAN, John.Greek sculpture: the classical period: a handbook. Nova York: Thames \& Hudson, 1985.

BOARDMAN, John.Greek sculpture: the late classical period and sculpture in colonies and overseas. Nova York: Thames \& Hudson, 1995.

BOCKELBERG, Sibylle von. Die friese vom Hephaisteion. In: Antike plastik XVIII. Berlin: Gebr. Mann, 1979, p. 23-50.

BOL, Peter C. (ed.). Die geschichte der antiken bildhauerkunst. Mainz: P. von Zabern, 2002-2010. BOL, Peter C. (ed.). Die geschichte der antiken bildhauerkunst II. Klassische plastik. Mainz: Philip von Zabern, 2004.

BONFANTE, Larissa. Nudity as a costume in classical art. American Journal of Archaeology, v. 93, p. 543-570, 1989.

BRINKMANN, Vinzenz. Die polychromie der archaischen und frühklassischen Skulptur. Munique: Bierig \& Brinkmann, 2003.

BRINKMANN, Vinzenz; SCHOLL, Andreas (eds.). Bunte Götter: die farbigkeit antiker skulptur. Eine ausstellung der antikensammlung. Berlin: Staatlichen Museen zu Berlin, 2010.

BROMMER, Frank. Die skulpturen der Parthenon-Giebel. Katalog und untersuchung. Mainz: Philip von Zabern, 1963.

BROMMER, Frank. Die Metopen des Parthenon. Katalog und untersuchung. Mainz: Philip von Zabern, 1967.

BROMMER, Frank. Der Parthenonfries. Katalog und untersuchung. Mainz: Philip von Zabern, 1977. BUITRON-OLIVER, Diana. Douris: a master-painter of athenian red-figure vases. Mainz: Philip von Zabern, 1995.

BÜTTNER, Nils. Geschichte der landschaftsmalerei. Munique: Hirmer, 2006.

CAMP, John M. The athenian agora: Excavations in the heart of classical Athens. London: Thames e Hudson, 1986.

CAMP, John M.; MAUZY, Craig A. (eds.). The athenian agora: new perspectives on an ancient site. Mainz: Philip von Zabern, 2009.

CARROLL-SPILLECKE, Maureen. Landscape depictions in greek relief sculpture: Development and conventionalization. Frankfurt; Berna; Nova York: P. Lang, 1985.

Caterina Maderna-Lauter. In: BOL, Peter C. (ed.). Die Geschichte der antiken Bildhauerkunst I: frühgriechische plastik. Mainz: Philip von Zabern, 2002.

CHAZALON, Ludi. L'arbre et le paysage dans la céramique attique archaïque à figures noires et à figures rouges. Annali di archeologia e storia antica, n. 2, p. 103-131, 1995.

DIETRICH, Nikolaus. Figur ohne Raum? Bäume und felsen in der attischen vasenmalerei des 6. und 5. Jahrhunderts $v$. Chr. Berlin: De Gruyter, 2010.

DIETRICH, Nikolaus. Das attribut als bildwissenschaftliches problem in der griechisch-römischen kunst (no prelo).

ELLIGER, Wolfgang. Die darstellung der landschaft in der griechischen dichtung. Berlin: De Gruyter, 1975.

ELLINGHAUS, Christian. Die Parthenonskulpturen. Der Bauschmuck eines öffentlichen monuments der demokratischen gesellschaft Athens zur zeit des Perikles - techniken in der bildenden kunst zur tradierung von aussagen. Hamburgo: Verlag Dr. Kova, 2011.

ERHARDT, Wolfgang. Zu Darstellung und Deutung des Gestirngötterpaares am Parthenon. Jahrbuch des Deutschen Archäologischen Instituts, v. 119, p. 1-39, 2004.

FEHL, Philipp. The rocks of the Parthenon frieze, Journal of the Warburg and Courtauld Institutes, v. 24, p. 1-44, 1961.

FREYER-SCHAUENBURG, Brigitte. Bildwerke der archaischen zeit und des strengen stils. Samos 11. Bonn: R. Habelt, 1974. 
FURTWÄNGLER, Adolf; REICHOLD, Karl. Griechische Vasenmalerei. Munique: F. Bruckmann, 1904-1932.

GIULIANI, Luca. Bild und mythos. Geschichte der bilderzählung in der griechischen kunst. Munique: C.H. Beck, 2003.

GIULIANI, Luca. Der Koloss der Naxier. In: GIULIANI, Luca (ed.). Meisterwerke der antiken kunst. Munique: C.H. Beck, 2005, p. 3-27.

HAMIAUX, Marianne. Les sculptures grecques I. Des origins à la fin du IVème siècle avant J.-C. Paris: Éditions de la réunion des musées nationaux, 2001.

HAUG, Annette. Die Entdeckung des Körpers. Körper- und Rollenbilder im Athen des 8. und 7. Jahrhunderts v. Chr. Berlin: De Gruyter, 2012.

HEDREEN, Guy M. Capturing Troy. The narrative functions of landscape in archaic and early classical greek art. Ann Arbor: University of Michigan Press, 2001.

HEINEMANN, Margret. Landschaftliche elemente in der griechischen kunst bis polygnot. Bonn: F. Cohen, 1910.

HIMMELMANN, Nikolaus. Bemerkungen zur geometrischen plastik. Berlin: Gebr. Mann, 1964. HIMMELMANN, Nikolaus. Grundlagen der griechischen pflanzendarstellung. Nordrhein-Westfälische Akademie der Wissenschaften. Geisteswissenschaften (Vorträge). Paderborn: Schöningh, 2005.

HÖLSCHER, Fernande. Gottheit und Bild - Gottheit im Bild. In: BIELFELDT, Ruth (ed.). Ding und Mensch in der Antike. Gegenwart und Vejagegenwärtigung. Akademiekonferenzen (Heidelberger Akademie der Wissenschaften), v. 16, p. 239-256. Heidelberg: Winter, 2014.

HÖLSCHER, Tonio. Körper, handlung und raum als sinnfiguren in der griechischen kunst und kultur. In: HÖLKESKAMP, Karl-Joachim et al. (eds.). Sinn (in) der antike. orientierungssysteme, Leitbilder und wertkonzepte im altertum. Mainz: P. von Zabern, 2003.

HÖLSCHER, Tonio. Die griechische kunst. Munique: C.H. Beck, 2007.

HÖLSCHER, Tonio. Architectural sculpture: Messages? programs? Towards rehabilitating the notion of 'Decoration'. In: SCHULTZ, Peter; HOFF, Ralf von den (eds.). Structure, image, ornament. Architectural sculpture in the greek world. Proceedings of an international conference held at the American School of Classical Studies, 27-28 November 2004. Oxford; Oakville: Oxbow Bools, 2009. HÖLSCHER, Tonio. Bilderwelt, Lebensordnung und die rolle des Betrachters im antiken Griechenland. In: DALLY, Ortwin; MORAW, Susanne; ZIEMSSEN, Hauke (eds.). Bild - Raum Handlung. Perspektiven der Archäologie. Berlin; Boston: De Gruyter, 2012.

HÖLSCHER, Tonio. Im Bild noch lebendiger als in Wirklichkeit. Bildwerke, Lebewesen und Dinge im antiken Griechenland. In: BIELFELDT, Ruth (ed.). Ding und Mensch in der Antike. Gegenwart und Vejagegenwärtigung. Akademiekonferenzen (Heidelberger Akademie der Wissenschaften), v. 16, p. 163-194. Heidelberg: Winter, 2014.

HURWIT, Jeffrey M. The representation of nature in early greek art. In: BUITRON-OLIVER, Diana (ed.). New perspectives in early greek art. Proceedings of the symposium. Washington DC, 1991, p. 33-62.

IMMERWAHR, Henry R. Attic Script: a Survey. Oxford: Clarendon Press, 1990.

JENKINS, Ian. The Parthenon frieze. London: The Trustees of the British Museum, 1994.

KAMINSKI, Gabriele. Die skulpturen des Zeustempels von Olympia. In: BOL, Peter C. (ed.). Die Geschichte der Antiken Bildhauerkunst II. Klassische plastik. Mainz: Philip von Zabern, 2004, p. 33-47. KARANASTASSIS, P. Hocharchaische Plastik. In: BOL, Peter C. (ed.). Die Geschichte der antiken Bildhauerkunst I: frühgriechische plastik. Mainz: Philip von Zabern, 2002.

KNELL, Heiner. Mythos und Polis. Bildprogramme griechischer Bauskulptur. Darmstadt: Wissenschaftliche Buchgesellschaft, 1990.

KUNISCH, Norbert. Griechische Fischteller. Natur und Bild. Berlin: Gebr. Mann, 1989.

KUNZE-GÖTTE, Erika. Beobachtungen zur darstellungsweise sepulkraler thematik auf weißgrundigen lekythen. In: SCHMIDT, Stefan; Oakley, John H. (eds.). Hermeneutik der bilder. beiträge zur ikonographie und interpretation griechischer vasenmalerei, Beihefte zum CVA, $v .4$. Munique: C.H. Beck, 2009.

LA ROCCA, Eugenio. Amazzonomachia. Le sculture frontonali del tempio di Apollo Sosiano. Roma: De Lucca, 1985.

LA ROCCA, Eugenio. Lo spazio negato: la pittura di paesaggio nella cultura artistica greca e romana. Milão: Electa, 2008.

LISSARRAGUE, François. Iconographie de Dolon le Loup. Revue Archéologique, v. 1, p. 3-30, 1980. 
LISSARRAGUE, François. Autour du Guerrier. In: BÉRARD, Claude et al. (ed.). La cité des images: religion et société en Grèce antique. Paris: F. Nathan, 1984, p. 35-47.

LISSARRAGUE, François. Paroles d'images: remarques sur le fonctionnement de l'écriture dans l'imagerie attique. In: CHRISTIN, Anne-Marie (ed.). Ecritures II. Paris: Sycomore, 1985, p. 71-95. LISSARRAGUE, François. Un flot d'images. Une esthétique du banquet grec. Paris: Éditions Adam Biro, 1987.

LISSARRAGUE, François. L'autre guerrier: archers, peltastes calvaliers dans l'imagerie attique. Paris; Roma: La Découvejate, École Française de Rome, 1990.

LISSARRAGUE, François. Graphein: écrire et dessiner. In: BRON, Christiane; KASSAPOGLOU, Effy (eds.). L'image en jeu. De l'antiquité à Paul Klee. Yens-sur-Morges: Édition Cabédita, 1992, p. 189-203.

LISSARRAGUE, François. Epiktetos egraphsen. The writing on the cup. In: GOLDHILL, Simon; OSBORNE, Robin (eds.). Art and text in ancient Greek culture. Cambridge: Cambridge University Press, 1995, p. 12-27

LISSARRAGUE, François. Publicity and performance. Kalos inscriptions in Attic vase painting. In: GOLDHILL, Simon; OSBORNE, Robin (eds.). Performance culture and Athenian democracy. Cambridge: Cambridge University Press, 1999a, p. 359-373.

LISSARRAGUE, François. Vases grecs: les athéniens et leurs images. Paris: Hazan, 1999b.

LISSARRAGUE, François. Ajax, corps et armes. In: COLPO, Isabella; FAVARETTO, Irene; GHEDINI, Francesca (eds.). Iconographia 2000000000000,06. Gli eroi di Omero. Atti del convegno internazionale Taormina 20-22.2006. Rome: Edizioni Quasar, 2007, p. 21-32.

LISSARRAGUE, François. Corps et armes: figures grecques du guerrier. In: DASEN, Véronique; WILGAUX, Gérome (eds.). Langages et métaphores du corps dans le monde antique. Rennes: Presses universitaires de Rennes, 2008, p. 15-27.

LISSARRAGUE, François. L'image mise en cercle. In: VILLANUEVA-PUIG, Marie-Christine (ed.). Images mises en forme. Mètis, Anthropologie des mondes grecs anciens, $v$. 7. Paris: Daedalus, 2009a, p. 13-41.

LISSARRAGUE, François. Reading images, looking at pictures, and after. In: SCHMIDT, Stefan; OAKLEY, John H. (eds.). Hermeneutik der bilder. Beiträge zur ikonographie und interpretation griechischer vasenmalerei. Munique: C.H. Beck, 2009b, p. 15-22.

LISSARRAGUE, François. La place des mots dans l'imagerie attique. Pallas, v. 93, p. 69-79, 2013. LÖWY, Emanuel. Die naturwiedergabe in der älteren griechischen kunst. Roma: Loescher \& Co, 1900. MADERNA-LAUTER, Caterina. Spätarchaische Plastik In: BOL, Peter C. (ed.). Die Geschichte der antiken Bildhauerkunst I: frühgriechische plastik. Mainz: Philip von Zabern, 2002.

MARTENS, Didier. Une esthétique de la transgression. Le vase grec de la fin de l'époque géométrique au début de l'époque classique. Bruxelas: Classe de beaux-arts, Académie royale de Belgique, 1992. MARTINI, Wolfram. Die archaische plastik der griechen. Darmstadt: Wissenschaftliche Buchgesellschaft, 1990.

Mattusch, Carol. Greek bronze statuary: from the beginning through the fifth century B.C. Ítaca; Londres: Cornell University Press, 1988.

MARTINI, Wolfram. Classical Bronzes: The Art and Craft of Greek and Roman Statuary, Ítaca; Londres: Cornell University Press, 1996.

MARTINI, Wolfram. Enduring bronze: ancient art, modern views. Los Angeles: Getty Conservation Institute, 2014.

MEISTER, Jan Bernhard. Der Körper des princeps. Zur problematik eines monarchischen körpers ohne monarchie. Stuttgart: Franz Steiner Verlag, 2012.

MUTH, Susanne. Als die Gewaltbilder zu ihrem Wirkungspotential fanden. In: SEIDENSTICKER, Bernd; VÖHLER, Martin (eds.). Gewalt und Ästhetik : zur Gewalt und ihrer Darstellung in der griechischen Klassik. Berlin: De Gruyter, 2006.

MUTH, Susanne. Gewalt im Bild. Das phänomen der medialen Gewalt im Athen des 6. und 5. Jahrhunderts $v$. Chr. Berlin: De Gruyter, 2008.

MUTH, Susanne; PETROVIC, Ivana. Medientheorie als Chance: Überlegungen zur historischen Interpretation von Texten und Bildern. In: CHRISTIANSEN, Birgit; THALER, Ulrich (eds.). Ansehenssache: formen von prestige in kulturen des altertums, Münchner Studien zur Alten Welt v. 9. Munique: Utz, 2012, p. 281-318.

NELSON, Lucie G. The rendering of landscape in greek and south italian vase painting. Dissertação (Mestrado), State University of New York. Nova York, 1976. 
OHLY, Dieter. Die Aegineten I. Die ostgiebelgruppe. Munique: C.H. Beck, 1976.

OSBORNE, Robin. The viewing and obscuring of the Parthenon frieze. Journal of hellenic studies, v. 107, p. 98-105, 1987.

OSBORNE, Robin. Framing the Centaur. In: OSBORNE, Robin; GOLDHILL, Simon (eds.). Art and text in ancient greek culture. Cambridge; Nova York: Cambridge University Press, 1994, p. 52-84. OSBORNE, Robin. Archaic and classical greek art. Oxford: Oxford University Press, 1998.

OSBORNE, Robin. Archaic and classical greek temple sculpture and viewer In: RUTTER, Keith; SPARKES, Brian (eds.). Word and image in ancient Greece. Edimburgo: Edinburgh University Press, 2000, p. 228-246.

OSBORNE, Robin. The narratology and theology of architectural sculpture, or What you can do with a chariot but can't do with a satyr on a Greek temple. In: SCHULTZ, Peter; VON DEN HOFF, Ralf (eds.). Structure, image, ornament. Architectural sculpture in the greek world. Proceedings of an international conference held at the American School of Classical Studies, 27-28 November 2004. Oxford; Oakville: Oxbow Books, 2009, p. 2-12.

OSBORNE, Robin; PAPPAS, Alexandra. Writing on archaic greek pottery. In: NEWBY, Zahra; LEADER-NEWBY, Ruth (eds.). Art and inscriptions in the ancient world. Cambridge; Nova York: Cambridge University Press, 2007, p. 131-155.

PALAGIA, Olga. Pediments of the Parthenon. Monumenta Graeca et Romana VII. Leiden; Nova York; Köln: E.J. Brill, 1993.

PFITZNER, Alfred. Die funktionen des landschaftlichen elementes in der streng rotfigurigen griechischen vasenmalerei. Rostock: C. Hinstorffs Hofbuchdruckerei, 1937.

PFUHL, Ernst. Malerei und zeichnung bei den griechen. Munique: Bruckmann, 1923.

PLATT, Verity. Facing the Gods. Epiphany and representation in Graeco-Roman art, literature, and religion. Cambridge; Nova York: Cambridge University Press, 2011.

RICHTER, Gisela. Red-figure athenian vases in the Metropolitan Museum of Art. New Haven: Yale University Press, 1936.

RICHTER, Gisela. Kouroi, archaic greek youths: a study of the development of the kouros type in greek sculpture. Londres; Nova York: Phaidon, 1970.

RIDDER, André de. Catalogue des vases peints de la Bibliothèque Nationale. Paris: Ernest Leroux, 1902. RIDGWAY, Brunilde S. The severe style in greek sculpture. Princeton: Princeton University Press, 1970.

RIDGWAY, Brunilde S. Fifth century styles in greek sculpture. Princeton: Princeton University Press, 1981.

ROLLEY, Claude. La sculpture grecque. La période classique. Paris: Picard, 1999.

SCHEFOLD, Carl. Die griechen und ihre nachbarn. Propyläen-Kunstgeschichte, v. 1, p. 39-41, 1967. SCHRADER, Hans (ed.). Die archaischen Marmorbildwerke der Akropolis. Frankfurt: V. Klostermann, 1939.

SCHWAB, Katherine. New Evidence for Parthenon East Metope 14. In: SCHULTZ, Peter; HOFF, Ralf von den (eds.). Structure, Image, Ornament. Architectural Sculpture in the Greek World. Proceedings of an international conference held at the American School of Classical Studies, 27-28 November 2004. Oxford; Oakville: Oxbow Books, 2009, p. 79-86.

SIEBERT, Gérard (ed.). Nature et paysage dans la pensée et l'environnement des civilisations antiques. Actes du Colloque de Strasbourg, 11-12 jun. 1992. Paris: Broccard, 1996.

SNELL, Bruno. Die Entdeckung des Geistes: Studien zur Entstehung des europäischen Denkens bei den Griechen. Göttingen: Vandenhoeck und Ruprecht, 1975.

SPIEß, Angela B. Der Kriegerabschied aufattischen Vasen der archaischen Zeit, Frankfurt: Lang, 1992. SQUIRE, Michael. Embodied Ambiguities on the Prima Porta Augustus. In: Art History, v. 36, p. 242-279, 2013.

STEINER, Ann. Reading Greek Vases. Cambridge: Cambridge University Press, 2007.

VERNANT, Jean-Pierre. De la présentification de l'invisible à l'imitation de l'apparence. In: Image et signification. Paris: Rencontres de l'école du Louvre, 1983, p. 25-37.

VERNANT, Jean-Pierre. Corps obscurs-corps éclatants. In: Le temps de la réflexion, v. 7: Corps des dieux. Paris: Gallimard, 1986, p. 30-33.

WOERMANN, Karl. Die landschaft in der kunst der alten völker. Eine geschichte der vorstufen und anfänge der landschaftsmalerei. Munique: T. Ackermann, 1876.

ZANONI, Ivo. Natur- und landschaftsdarstellungen in der etruskischen und unteritalischen Wandmalerei. Frankfurt; Berna; Nova York: P. Lang, 1998. 